\title{
Cobertura informativa de la violencia vinculada al narcotráfico en Tijuana durante el periodo histórico coyuntural 2008-2011: El caso de los periódicos El Mexicano y Frontera
}

Milthon Minor Montes ${ }^{1}$

https://doi.org/10.36105/stx.2018n1.11

\section{Resumen}

En este artículo de investigación se identifica y analiza la cobertura informativa de la violencia vinculada al narcotráfico en Tijuana, Baja California, México, en un momento histórico coyuntural, 2008-2011, en el que la violencia se desbordó en la región. En el estudio se analizan las temáticas expuestas en las noticias titulares de las portadas de los periódicos tijuanenses El Mexicano y Frontera. Su base teórico-metodológica contempla la teoría del establecimiento de la agenda y la propuesta de selección temática de López (2010). Se concluye que la cobertura de la violencia en los diarios obedece a una estrategia principalmente reactiva-coyuntural. El Mexicano presentó una perspectiva oficial y de legitimación gubernamental; Frontera, una perspectiva tipo diario popular, agenda establecida con base en los acontecimientos delictivos. En ambos casos destaca una tendencia de comportamiento acrítico generalizado, incoherente con las necesidades de divulgación de los acontecimientos para sus lectores, sin posibilidades de establecer debate público. ${ }^{2}$

\footnotetext{
1 Maestro en Comunicación por la Universidad de Guadalajara (UdeG) y Licenciado en Ciencias de la Comunicación por la Universidad Autónoma de Baja California (UABC). Reportero de medios impresos y profesor de Análisis y Diseño de Contenidos en la Universidad del Valle de México, sede Mexicali. Ha sido asistente de investigación sobre temas de migración para el cIESAS Occidente, y ha desarrollado programas de comunicación externa para la Escuela de Ingeniería y Negocios Guadalupe Victoria de la UABC en Mexicali, Baja California.

2 Este artículo se realizó con base en la tesis Cobertura y tratamiento informativo de la violencia vinculada al narcotráfico en Tijuana: Estrategias de encuadre para su interpretación. El caso de los periódicos El Mexicano y Frontera (2008-2011), hecha como parte de la Maestría en Comunicación del Departamento de Estudios de la Comunicación Social, de la Universidad de Guadalajara, y con recursos del Conacyt.
} 


\section{Palabras clave}

Cobertura periodística, violencia, narcotráfico, prensa escrita en México, Tijuana.

\section{Introducción}

El tráfico de drogas ilegales en México es un tema abordado en los medios de comunicación históricamente. El fenómeno se ha expuesto como parte de la realidad social del país en la prensa escrita, desde la prohibición del cultivo y consumo de la mariguana y la adormidera en la segunda década del siglo XX (Astorga, 1996, 2012). En los últimos diez años su aparición se dio con mayor constancia y, como asunto con alto valor noticioso, ha ocupado espacios que tradicionalmente eran establecidos para temas de información general, política, salud, educación, entre otros; pero además ha formado parte del discurso oficial de manera sobresaliente. Lo anterior se debe a que, al tomar posesión como presidente de la República, en diciembre de 2006, Felipe Calderón Hinojosa colocó a la seguridad pública como un tema central de su administración. A través de su retórica de legitimación, y como un acto de gobierno, declaró la guerra al narcotráfico (Norzagaray, 2010). La arenga de Calderón trajo consigo la movilización de 50 mil elementos del Ejército y la Marina a lo largo y ancho del país, a través de diversos operativos militares en distintas entidades federativas. ${ }^{3}$

La estrategia establecida por la Federación, a pesar de ser triunfalista, no obtuvo éxito. ${ }^{4}$ En un periodo de cinco años, de diciembre de 2006 a septiembre de 2011, la lucha contra el narcotráfico provocó, según datos de la Procuraduría General de la República (PGR), 47,515 muertes (Casillas, 2012). En contraste, cifras de la organización Amnistía Internacional señalan que al menos 60 mil personas fueron víctimas de homicidios violentos de 2006 a 2012. La Organización Panamericana de la Salud en su Informe sobre Salud en las Américas 2012, capítulo México, señala que la violencia cobró la vida de 50 mexicanos cada 24 horas, ante el aumento de los asesinatos relacionados con el tráfico de drogas en el

\footnotetext{
3 El primer despliegue importante se dio en Michoacán, en diciembre de 2006. En 2007 se amplió la estrategia a otros estados, con el Operativo Baja California, centrado en Tijuana, el Operativo Chihuahua, el Operativo Culiacán-Navolato, en Sinaloa, el Operativo Sierra Madre, en Sinaloa y Durango, el Operativo Nuevo León-Tamaulipas, y el Operativo Guerrero (Escalante, 2011).

4 De acuerdo con Astorga y Shirk (2010), el ataque gubernamental al narco, caracterizado por las detenciones o abatimiento de los líderes de las redes de traficantes (o miembros de cualquier eslabón de la cadena ilegal) y la incautación de armas y estupefacientes (además de las disputas entre grupos por los territorios de trasiego y distribución de la droga), generaron un conflicto mayor: la diversificación de actividades delictivas, como el secuestro y crimen a menor escala; "las células de los cárteles se han descentralizado y fraccionado" (p. 19).
} 
país. Esto se dio a través de actos como balaceras en lugares céntricos (cerca de escuelas, por ejemplo); personas desaparecidas, luego encontradas con tiros de gracia en la cabeza; personas deshechas en ácido, mutiladas o colgadas en espacios públicos; masacres a niños, jóvenes, adultos, migrantes... en zonas urbanas y rurales. Tragedias que se constituyeron discursiva y pragmáticamente en los medios de comunicación como "narcoviolencia".

El tráfico de drogas ilegales es un fenómeno que se somete a factores globales y locales. En México, a pesar de ser un asunto generalizado, por su geopolítica diversa se presenta de forma segmentada; existen múltiples cárteles, y cada cártel muestra un comportamiento propio, con gran influencia regional (con características específicas entre quienes se ubican en el norte, centro o sur del país). ${ }^{5}$ De la misma forma, el abordaje noticioso sobre el narcotráfico se registra de forma peculiar en cada región, dependiendo de las características editoriales de cada medio y de su contexto (MEPI, 2010, 2011). No es lo mismo cubrir el fenómeno en Chihuahua, Sinaloa, Tamaulipas o Baja California. ${ }^{6}$

Este estudio analiza la cobertura de la violencia vinculada al narcotráfico en los periódicos El Mexicano y Frontera, originarios de Tijuana, Baja California. Este municipio se encuentra ubicado al noroeste de México. La cercanía limítrofe del municipio con San Diego, California, en los Estados Unidos de América, da gran relevancia al territorio, en cuestión de las posibilidades de contrabando de estupefacientes, ante la importante demanda de drogas de aquel país (Sánchez, 2011). Su histórica violencia se ve desbordada en las calles de Tijuana a partir de $2008,{ }^{7}$ lo que repercutió directamente en la vida de más de un millón 500 mil habitantes; en este año los tijuanenses empezaron a sufrir un incremento de inseguridad ciudadana, generada por el alza de secuestros, privaciones ilegales de la libertad y asesinatos, delitos relacionados con los enfrentamientos entre los miembros del cártel de los hermanos Arellano Félix y el cártel de Sinaloa (las causas y datos se describirán en el apartado referencial), y el ataque directo de las autoridades federales al narco. Es a partir de 2011 que se empieza a dar una disminución de los delitos de gran impacto, ante supuestos arreglos de los cárteles rivales (Stratfor, 2012).

5 La forma estratégica de operar de cada grupo tiene relación con su antecedente histórico de formación (su raíz), la vida sociocultural de la zona en la que se anida, su espacio geopolítico de desarrollo y su estilo de dominio (ejercicio de poder a través de corrupción, violencia o negociación).

6 Aunque la violencia del narcotráfico ya ha generado conflictos en todas las salas de redacción del país, las características de la práctica periodística no son las mismas en los diversos entornos hostiles.

7 La inseguridad ciudadana en Tijuana se evidenció desde 2006, año en el que los secuestros provocaron manifestaciones públicas de temor, como fue la marcha ciudadana por la paz, que recorrió todo Baja California. La caminata tuvo una duración de 16 días; inició el sábado 21 de octubre en San Quintín y recorrió 500 kilómetros hasta finalizar en Mexicali, capital del estado, el domingo 5 de noviembre. Pero fue en 2008 cuando los asesinatos y otros delitos de alto impacto se incrementaron de manera sobresaliente. 
Los acontecimientos dados son de indiscutible importancia e interés para la ciudadanía, la cual cotidianamente se entera de los hechos a través de diversas actividades de interacción comunicativa. Una de las principales fuentes de conocimiento sobre aquellos sucesos, a los que las personas no tienen acceso directo, es la prensa, que tiene como objetivo recabar la información, sistematizarla y después reproducirla a manera de noticias. Por lo tanto, las noticias son una fuente de socialización de la realidad, y representan un vínculo entre los acontecimientos y los lectores. De acuerdo con Lorenzo Gomis (1991), aunque las noticias se compongan de hechos, no cualquiera de éstos llega a ocupar un espacio mediático. Dentro de la masa informativa a la que tienen acceso los periódicos cada día, sólo algunos sucesos sí están sujetos a los criterios de noticiabilidad; es decir, serán seleccionados y presentados al público como "información legitimada".

La selección temática que realizan los periodistas, y que después emiten, contribuiría a construir las imágenes que nos formamos del mundo (Lippmann, 2003), las imágenes que nos formamos sobre nuestro entorno. Para McCombs (1996), lo que los medios de comunicación presentan día a día constituye una agenda de temas que serán de interés preponderante para los lectores, es decir, que los medios establecen en qué deben pensar y sus prioridades.

Ante un fenómeno de impacto multidimensional (social, económico, cultural, de salud, democrático), se esperaría que el conocimiento sobre los hechos que los ciudadanos reciben de los medios de comunicación estuviera apegado a sus verdaderas necesidades para enfrentarlo. Por lo tanto, es de gran relevancia preguntarnos ¿̇cómo fue la cobertura realizada por los medios impresos tijuanenses El Mexicano y Frontera sobre la violencia vinculada al narcotráfico en Tijuana? ¿Cuáles fueron las temáticas que predominaron en los titulares de las portadas de los diarios que son los casos de estudio? El análisis se enfoca en el momento histórico coyuntural 2008-2011. Los diarios caso de estudio representan $90 \%$ del mercado de periódicos en el municipio, y se consideran del tipo generalista, es decir, no enfocados a la nota roja.

El aspecto teórico-metodológico se desarrolló con base en el modelo de establecimiento de la agenda por McCombs y Shaw en 1972 (McCombs, 1996; McCombs et al., 2003) y de selección temática, que forma parte del modelo de estrategia de encuadre de Pablo López Rabadán (2010). Al hablar de cobertura informativa "me refiero a las noticias que construyen la agenda en los medios de comunicación sobre un tema determinado (qué temas se incluyen, cuánto de los temas se abarca)" (Minor, 2016, p. 89). A partir de la obtención del análisis cuantitativo, se pretende identificar las temáticas de la realidad social seleccionadas, a las que fueron expuestos los lectores, y la estrategia de cobertura implementada por cada medio. Asimismo, esta evidencia nos permitirá inferir el tipo de periodismo impreso diario que se presentó en la región en un momento de gran importancia para sus habitantes. 


\section{Medios de comunicación y violencia vinculada al narco}

En medio de una crisis con características de depredación y duración prolongada, las armas mortales no fueron las únicas herramientas utilizadas por los actores en disputa. Los medios de comunicación se convirtieron en instrumentos que jugaron un papel preponderante como "arenas centrales" en la sociedad, lo que provocó la lucha por el control de la agenda informativa. Siguiendo al investigador colombiano Jorge Bonilla, quien analiza el conflicto armado en su país, estos grupos buscarían "gestionar en la esfera pública los marcos de interpretación con el propósito de obtener el control hegemónico de las representaciones de la sociedad”. La disputa por la agenda tendría como propósito "movilizar, hacer visibles, ocultar y legitimar sus causas" (2002, p. 54). Es así que "los liderazgos regionales de los grupos criminales dejaron de imponerle el silencio a los medios [de comunicación] para exigirles espacio" (Artículo 19, 2012, p. 40). Por lo tanto, el escenario para ejercer el periodismo en México no ha sido nada sencillo; acudir a cubrir algún acontecimiento se llegó a considerar tan peligroso como abordar un acto bélico internacional, pero sin las herramientas necesarias ni el conocimiento especializado de un periodista de guerra (Hernández \& Rodelo, 2010).

En 2012, el organismo internacional Reporteros Sin Fronteras clasificó al país como la nación más peligrosa del continente americano para realizar el ejercicio de informar; mientras que Artículo 19 reportó 72 casos de periodistas asesinados por razones presuntamente vinculadas con su trabajo, del año 2000 a 2012. La investigadora de la Universidad de Guadalajara Frida Rodelo, al analizar el caso de los periodistas de Culiacán, Sinaloa, estableció que ante el riesgo que existe al cubrir el narco, los reporteros han tomado medidas de seguridad, lo que ha definido como un modelo de periodismo precavido (2008); éstos realizan sus reportes sin investigación, sin contexto, de forma pragmática, y con censura, para evitar ser víctimas de los traficantes. ${ }^{8}$ Rodelo (2008) agrega que la debilidad del Estado permite que se fomente la corrupción o impunidad que favorece las limitaciones a la libertad de prensa.

Para los comunicadores, abordar eventos inesperados de violencia en entornos hostiles, o trabajar amenazados ante la lógica de la "plata o plomo", implicó dejar de cumplir con su misión, no cubrir sucesos violentos o dejar de publicarlos, lo que ha dado como resultado “apagones informativos” (Hernández, 2010) o "vacíos de información” (MEPI, 2010). Auto-

8 Frida Rodelo (2008), en su tesis de maestría en Ciencias Sociales titulada Ejercicio de la libertad de prensa y sus limitaciones en entornos violentos. El caso de los periodistas de Culiacán, Sinaloa, México, propone un modelo sobre este periodismo precavido. "El periodismo precavido sobre temas delicados es, en resumidas cuentas, lo que puede ser en términos económicos y de seguridad: periódicos y periodistas realizan un periodismo sobre temas delicados mediados por la razón de mercado y cuyo valor principal es la sobrevivencia” (2008, p. 150). 
censura que va en contra de los artículos $6^{\circ}$ y $7^{\circ}$ de la Constitución Política de los Estados Unidos Mexicanos, que establecen que la información es considerada como un derecho individual y colectivo. No tocar un tema de interés comunitario reporta un impacto social y democrático para la nación.

Otro aspecto sobresaliente de las coberturas de la violencia vinculada al narcotráfico y crimen organizado es el "analfabetismo" con el que los periodistas se acercaron a los agresivos acontecimientos cotidianos: a través de la nota roja o la nota policiaca, que se caracteriza por transmitir sucesos de quiebre social, y que se expone con elementos espectaculares, imágenes y encabezados llamativos. Se trata de la reproducción de los partes policiacos, necropsias o expedientes judiciales; presentaciones de detenidos en ruedas de prensa y la descripción de los hechos. En un primer momento, después de la declaración de guerra de Calderón, como resultado de los primeros ataques, el conteo de los muertos se presentó como cartelera en las portadas de los diarios; el score, como se estila en el ámbito deportivo (Hernández \& Rodelo, 2010), o el ejecutómetro (Turati, 2010), la sumatoria de muertos del día, semana, mes; por región, ciudad, estado, país; cifras cada vez más “voluptuosas”. La periodista Marcela Turati, de la Red de Periodistas de A Pie, reflexiona lo siguiente sobre la improvisada cobertura:

Se recogen las constancias del dolor con los mismos recursos con los que antes cubrimos los efectos de algunas tragedias naturales o hechos de violencia aislados, y quizás con el aturdimiento de quien no entiende lo que pasa, analfabetas a los nuevos códigos de sangre en los que exterminar al otro es la meta, en los que la saña es el mensaje y se expresa a través de cuerpos decapitados, calcinados, desaparecidos, disueltos en ácido, levantados, ejecutados, masacrados $[\ldots]$ (2010, p. 58).

La crítica hacia esta cobertura radica en que fueron olvidados los derechos humanos y la deontología periodística (Núñez, 2011) como eje central de las noticias. Además de que, como indica Waisbord (2000), la prensa es considerada como generadora de debate social para el fomento de la democracia, y su labor no debe quedar sólo en describir actos delictivos provocados por el narcotráfico, sino en explicar un fenómeno complejo, de orden social, político, económico, cultural y de salud (Sierra, 2010a). El periodista Álvaro Sierra señala que el fenómeno no se limita a un sólo aspecto que observar ni a una forma trivial de comunicarlo, por lo tanto:

Más allá de su fachada sangrienta, el narcotráfico es un fenómeno económico, con lógicas y explicaciones de mercado, que plantea a los gobiernos y a la sociedad no sólo desafíos de seguridad 
sin precedentes sino un enigma de mezclas de economía legal e ilegal y grupos clandestinos y poder político que es indispensable descifrar (Sierra, 2010b, p. 46-47).

Las noticias de los medios de comunicación, en un contexto tan peculiar, podrían priorizar diversos tratamientos criticables (Minor, 2016):

La reproducción del discurso oficial, emitido a través de los diferentes niveles de gobierno con el propósito de legitimar sus causas o deslegitimar a los otros (narcotráfico/crimen organizado).

La trivialización de los contenidos, al descontextualizar los hechos, encapsularlos, o presentar datos repetitivos (redundancia).

La ficcionalizacion de la violencia, proponer una visión ubicua, es decir, que es incontenible y está en todos lados (Nívea, 1994); por lo que parecería imposible atacarla como fenómeno (de no ser con más violencia legítima/gubernamental).

La dicotomía de la información, tratar los asuntos sólo como disputas entre buenos contra malos (de esta forma considerar el autoritarismo como única salida).

Y el sensacionalismo, ${ }^{9}$ que buscara propiciar un impacto veloz de atracción de lectores, a través de su selección temática y tratamiento altamente descriptivo, beneficiando el "mercadeo" de la información.

\section{Contexto Tijuana, agudización de la violencia}

Tijuana es un municipio joven, en 2016 cumplió 127 años de vida. Ubicado en Baja California, ${ }^{10}$ al noroeste de México, hace frontera con San Diego, California, de Estados Unidos de América. ${ }^{11}$ Como región contrasta por sus cualidades económicas y culturales, y por sus problemáticas de violencia social. La endémica presencia del narcotráfico en la entidad se entien-

9 "Sensacionalizar las noticias es un modo de comunicación que pretende llamar la atención del lector por medio de la vedetización de acontecimientos y personajes que se localizan habitualmente en la periferia del orden instituido" (Nívea, 1994, p. 143).

10 Baja California se convirtió en 1989 en la primera entidad en contar con un gobierno de oposición al Partido Revolucionario Institucional (PRI), a sólo un año del inicio de la administración del expresidente de la República Carlos Salinas de Gortari (1988-1994); desde entonces ha sido gobernado por el PAN.

11 Tijuana es una de las fronteras con mayor interacción trasnacional, en 2008 sus garitas registraron el cruce legal de 43, 764,104 personas (Ceesem, 2009a). De acuerdo con la investigadora Lilian Ovalle "este dinamismo de la población constituye un ambiente atractivo para los narcotraficantes que pueden llegar a esta ciudad y mantener su anonimato fácilmente, lo cual se dificulta en ciudades más tradicionales y cerradas” (2006a, p. 34). 
de bajo la demanda del mercado estadounidense para el consumo de drogas, y su contrabando es posible gracias a una red de complicidades y de protección por parte de diversos actores políticos de los tres niveles de gobierno, en México y Estados Unidos (Sánchez, 2011).

Aunque el desarrollo del narcotráfico en Tijuana es cronológicamente amplio, es a principios de los años ochenta del siglo XX que se conoce por primera vez de una operación estructurada de redes de traficantes de estupefacientes con mayor presencia, a la que después se le denominaría como cártel de Tijuana, hoy conocido como de los hermanos Arellano Félix (CAF). Dicho grupo lograría controlar el tráfico y mercadeo de marihuana y cocaína en el espacio territorial tijuanense por un largo periodo (Blancornelas, 2002). Después de más de dos décadas de dominio en Baja California, las fracturas internas de la organización agudizaron el problema de la violencia en 2008. Las detenciones y la muerte de quienes lideraban la región desde los años ochenta generaron un conflicto por el poder que derivó en la segmentación del grupo. Esta organización delictiva, además, debió disputarse el control de rutas y mercado de consumo con el cártel del Pacífico (o de Sinaloa), que es dirigido por Joaquín "el Chapo" Guzmán. ${ }^{12}$

Ante el incremento de la inseguridad, y como parte de la estrategia de "guerra" de Calderón, en enero de 2007 la Secretaría de Gobernación anunció la Operación Conjunta contra el Narcotráfico Tijuana. El gobierno federal envió, con el aval del gobierno panista de Baja California, a 3,296 elementos del Ejército, Marina, policías federales, entre otros, para enfrentar al crimen organizado en esta localidad. ${ }^{13}$ Esta estrategia de contención detonó los asesinatos a partir de 2008 en Tijuana. Sánchez (2011) explica que ante el bloqueo de accesos a la frontera a los cárteles, éstos debieron diversificar el tipo de delitos que cometían, recurriendo, además de su tradicional actividad de tráfico de drogas, a los secuestros y extorsiones a empresarios y miembros de la clase media alta local.

Durante 2008 y 2009, Baja California proyectó un alza de homicidios dolosos. De acuerdo con un análisis independiente con datos del Inegi, hecho por Fernando Escalante (2011), de 13.8 asesinatos por cada 100 mil habitantes en 2006 y 2007, el registro pasó a 40 homicidios por cada 100 mil habitantes los dos años posteriores. Es en Tijuana donde se presentaron $72 \%$ de estas muertes; este municipio cuenta con la mitad de los habitantes del estado. Según la Secretaría de Seguridad Pública de Baja California, en Tijuana hubo en 2007310 casos de personas muertas de forma dolosa y así continuó en $2008^{14}$. En

\footnotetext{
12 La información es registrada periodísticamente por el semanario tijuanense Zeta, semana del 15 al 21 de octubre de 2010. Número 1907, páginas de la 14-17.

$13 \mathrm{http} / /$ www.jornada.unam.mx/2007/01/03/index.php?section=politica\&article $=003 \mathrm{n} 1 \mathrm{pol}$

14 En octubre de 2008 fue arrestado el líder del CAF, Eduardo Arellano, en Tijuana, posteriormente, en el último trimestre de 2008, se desataron las muertes violentas vinculadas al narcotráfico.
} 
2009 se presentaron 553 asesinatos. El año más cruento fue 2010, con 688 defunciones dolosas; mientras que en 2011 se empezó a notar una disminución, al contabilizarse 418 homicidios (la cifra es aún mayor a la de 2007).

Las características de los asesinatos y su presentación pública no pasaron desapercibidas. Los casos son múltiples: el hallazgo de cabezas de jóvenes dentro de bolsas de plástico tiradas en la calle, acompañadas con mensajes enviados hacia los grupos rivales con los que mantenían disputas; personas decapitadas o mutiladas y después colgadas en pasos a desnivel dentro de la ciudad; tambos de plástico con restos humanos deshechos en ácido, abandonados también en calles céntricas, y con narcomensajes. En los casos de mayor discreción estos cuerpos eran enterrados en terrenos ubicados en zonas periféricas. Comandos armados que rafagueaban casas habitación, hiriendo a niños con esquirlas de balas; internos de centros de rehabilitación fusilados; balaceras en centros comerciales, restaurantes, centros nocturnos, casas cercanas a escuelas de nivel preescolar y primaria. ${ }^{15}$

La disputa entre cárteles creció hasta 2011, momento en el que ambos grupos llegaron a formar acuerdos en el uso de las rutas de trasiego de estupefacientes (Stratfor, 2012). La postura del gobierno federal sobre una baja en delitos de alto impacto en Tijuana es la del éxito obtenido a través del "Operativo Tijuana”, lo que convirtió a Baja California en "modelo a seguir" en el ataque al crimen organizado nacional, según el discurso establecido cotidianamente por Felipe Calderón, durante las recurrentes visitas realizadas al municipio de 2007 a $2012 .{ }^{16}$

\section{Selección de los diarios casos de estudio: El Mexicano y Frontera}

Durante el periodo de análisis, 2008-2011, Tijuana contaba con los periódicos El Mexicano, Frontera y El Sol de Tijuana, ${ }^{17}$ así como los semanarios Zeta y El Informador de Baja

15 Actos tan crueles que dieron origen a "personajes" como Santiago Meza López, "el Pozolero", detenido en Tijuana por disolver los cuerpos de alrededor de 300 personas en tambos de sosa cáustica para desaparecerlas, por órdenes del cártel de los Arellano Félix.

16 Por su parte, Raúl Ramírez Baena, dirigente de la Comisión Ciudadana de Derechos Humanos del Noroeste, explicó al periódico La fornada: "Fue una pacificación aparente; fue también el periodo en el que recibimos más denuncias de allanamientos ilegales, detenciones arbitrarias y, sobre todo, torturas. Y fue el periodo en el que aumentó escandalosamente el número de policías asesinados. Sólo en 2009 fueron más de 40 (tres o cuatro cada mes)" (Petrich, 2011).

17 En suma, estos tres medios representan menos de 70 mil ejemplares tirados al día, en una ciudad con más de 1.5 millones de personas. Las cifras de edición son otorgadas por parte de cada empresa en el Padrón de Medios Impresos de la Secretaría de Gobernación. 
California (Info Baja). La selección de sólo dos diarios se basó en hacer operativa la muestra y tomar aquellos que proporcionaran una amplia representatividad social. Sin considerar semanarios, por sus características editoriales (uno crítico-especializado, el otro comercial-gratuito) y su periodo de emisión (semanal). ${ }^{18}$

El Mexicano es un periódico de formato estándar, que inició operaciones en 1959. Cuenta con un tiraje de 29,190 ejemplares diarios (2010). Es de corte oficial, al pertenecer a una empresa con ligas directas al Partido Revolucionario Institucional (PRI). Su director general (propietario), Eligio Valencia Roque, ha sido diputado local y regidor por el PR I; el diario es cercano al sector empresarial y "empático" con el gobierno estatal del Partido Acción Nacional (PAN) que se encuentra en la gubernatura de Baja California desde 1989, por lo que el tiempo y la experiencia les ha permitido aprender a "interactuar cómodamente".

Frontera "salió a la luz" con un formato impreso tipo estándar y un corte editorial generalista en 1999; fue considerado como un medio conservador (Trujillo, 2000), distanciado del gobierno, y con una práctica de periodismo cívico ${ }^{19}$ (Hughes, 2009). A partir de 2008, su forma cambió a tabloide, $\mathrm{y}$ pasó de tener principalmente lectores de alto nivel adquisitivo $\left(\mathrm{ABC}+\right.$ jóvenes) a una audiencia de nivel socioeconómico bajo $(\mathrm{DE}) ;{ }^{20}$ lo cual tiene relación con una disminución del precio por ejemplar de 8 a 4 pesos y el cambio en su tipo de cobertura, según se verá en los resultados. Con estas estrategias, Frontera incrementó su circulación. De editar 21,978 ejemplares diarios en 2008 pasó a 32,700, en 2010. ${ }^{21}$

Es importante mencionar que, igual que la violencia, el contexto económico enmarcó el desarrollo de la prensa escrita en Baja California durante el lapso de análisis realizado. La recesión estadounidense, durante 2008 y 2009 , impactó a las empresas trasnacionales, nacionales y regionales en la frontera, lo cual generó un déficit en la adquisición de publicidad por parte del sector privado en la entidad y, por ende, una baja en los ingresos de los diarios, que representó el despido de personal del área de redacción (Minor, 2016) y administrativo. ${ }^{22}$

18 No contemplé a El Sol de Tijuana por contar con menor impacto y un tiraje de 6,791 ejemplares.

19 De acuerdo con Hughes, en el periodismo cívico: "los medios proveen información que ayuda a los ciudadanos a comunicar sus necesidades al gobierno, a someterlo a la rendición de cuentas, y a fomentar la deliberación y el debate" (2009, p. 20).

20 Publicidad de la empresa en la edición 202 mayo, 2009 de la revista MPM Tarifas y Datos de Medios Impresos.

21 De esta forma Frontera logró arrebatar una parte del mercado a El Mexicano, diario de mayor circulación históricamente en Tijuana. Se infiere que en su disputa por el mercado, Frontera sacrificó la calidad editorial, y fortaleció su estrategia de venta (Minor, 2016).

22 En contraste, un alza en la demanda de publicidad oficial ubicada en un presupuesto que, en suma, representa más de 459 millones de pesos para la entidad, en un periodo de siete años, de 2005 a 2011; y que comúnmente se eleva durante las temporadas electorales locales. De acuerdo al Informe El costo de la legitimidad. El uso de la publicidad oficial en las entidades federativas. http://publicidadoficial.com.mx/v2/ pdf/P.O.FINAL.pdf 


\section{Cobertura informativa y libertad de expresión}

Los inesperados acontecimientos violentos vinculados al narcotráfico en Tijuana, como lógica periodística, llamaron la atención de los medios impresos locales (López, 2009) y fueron exhibidos cotidianamente en sus portadas bajo la tipología de la nota roja. La razón de esta cobertura, señala Adela Navarro, se debe a que "el reportaje enfocado al narcotráfico y crimen organizado se encuentra en peligro de extinción” (2008, p. 13). La periodista es codirectora del semanario Zeta, medio que ha sufrido diversos asesinatos y atentados en contra de sus fundadores, y aun así insiste en llevar a cabo su cobertura especializada sobre las redes del narco y la corrupción política en Baja California y Baja California Sur. Navarro agrega que en otras redacciones locales de Tijuana se da la autocensura, generada por las amenazas que sufren sus periodistas. A continuación describe cómo cubren otros medios de comunicación el fenómeno en la zona:

El tema del narcotráfico se aborda en la mayoría de los medios como una nota informativa; la copia de un parte policiaco, la cita textual de una declaración oficial, en salvadas ocasiones a lo más que llega es a la transcripción de lo atestiguado y asentado en un expediente judicial. Muy pocas veces hay investigación de por medio (Navarro, 2008, p. 13).

El riesgo también se presenta de forma cotidiana, al acudir a reportear algún suceso policiaco, una balacera o un accidente, por ejemplo, Jorge Morales, subdirector editorial del periódico Frontera en 2008, expresó durante un foro internacional en Washington, Estados Unidos, que al cubrir algunos enfrentamientos entre las autoridades federales y militares y los grupos del narcotráfico en Tijuana, los periodistas quedaron atrapados en el "fuego cruzado", por lo que la empresa determinó que los reporteros debían utilizar chalecos antibalas. Asimismo, dijo que Frontera entregó a sus reporteros, junto con el manual de estilo y de ética de la organización, otro con las medidas de seguridad que debían tomar, se les capacitó sobre periodismo en entornos hostiles, y se evitó firmar este tipo de noticias, "tratando de minimizar los riesgos". Añadió que "por el momento no estamos investigando, por lo menos no de la forma como lo hacíamos anteriormente [sobre] temas del crimen organizado, porque creemos que no existen las garantías suficientes para hacerlo" (Morales, 2008, SD).

En entrevista personal con el autor de este artículo, en octubre de 2011, Enrique Sánchez Díaz, subdirector general de El Mexicano, señaló que para no tener problemas y que el narcotráfico no se metiera ni con los medios ni con los periodistas, de acuerdo con la experiencia, era necesario relatar sólo la "nota objetiva": "cuántos muertos, y las narracio- 
nes de los jefes policiacos, con la interpretación de los hechos”; olvidándose de realizar investigaciones. Tomando en cuenta sus palabras se establece que en el diario recurrieron a lo que Rodelo (2008) determinó como periodismo precavido. Sánchez dijo claramente: "Sabemos que cuando te metes con alguien del narcotráfico no hay poder en el mundo que te proteja, ni la policía ni nada, entonces hay autoprotección”, autoprotección que se convierte en autocensura. ${ }^{23}$

Desde otra perspectiva, la intención de las redes del narco de visibilizar sus actos violentos en contra de los miembros de los grupos rivales, perpetrándolos en espacios públicos, ${ }^{24}$ implicó el establecimiento (forzado) de una agenda a conveniencia. Como resultado, se transitó del riesgo por acudir a cubrir algún acontecimiento agresivo, al riesgo por no hacerlo o por censurar la información, como lo señalan Relly y González (2015) en una investigación sobre periodismo en la frontera norte de México. Las investigadoras refieren lo que sucedió a un diario tijuanense por decidir no publicar un "narcomensaje": "Al día siguiente, una cabeza decapitada con el mismo mensaje fue arrojada cerca de la caseta del guardia de seguridad del medio” (p. 309). Por recomendación de las autoridades, el periódico decidió dar a conocer el contenido del mensaje. Éste es sólo un ejemplo de cómo el crimen organizado buscaría influir en una agenda pública en Tijuana, como ya lo hacía en otros estados del país.

La ausencia de investigación y contexto limitaría la comprensión y solución del problema social generado por el fenómeno, al enfocarse a los acontecimientos criminales y no a las causas por las que se originó (Sierra 2010a, 2010b; Hernández \& Rodelo, 2010); lo que además contribuiría a incrementar la sensación de inseguridad de los tijuanenses (López, 2009).

\footnotetext{
23 Aparte de las limitaciones al trabajo de investigación sobre el crimen organizado/narcotráfico, surgieron algunos intentos de control/regulación informativa a la prensa desde lo local y lo nacional. En marzo de 2011, El Mexicano y Frontera firmaron el Acuerdo para la Cobertura Informativa de la Violencia, que tenía como propósito establecer lineamientos sobre cómo atender de forma editorial los asuntos relacionados con el crimen organizado. Asimismo, en abril de 2011, organizaciones empresariales y gubernamentales conformaron el Comité de Imagen y Percepción de Baja California. La labor de este nuevo organismo sería la de poner en marcha una serie de estrategias encaminadas a mejorar la imagen del estado, principalmente ante el mercado turístico del sur de California, y conformar un subcomité de imagen y medios que estableciera contacto con la prensa para disminuir la cantidad de notas rojas en las portadas de los diarios.

24 Cuerpos colgados en pasos a desnivel, narcovideos, la cabeza de un joven tirada en las inmediaciones del periódico Frontera en 2010.
} 


\section{Marco conceptual de la violencia vinculada al narco}

La violencia como acto, o como fenómeno social, cuenta con múltiples formas de presentarse, y se vincula directamente con el ejercicio de poder; por lo tanto, el término debe considerarse de manera plural (Imbert, 1992; Reguillo, 2011). No existe una sola definición que englobe todos sus aspectos. Diversos autores se han abocado a estudiarla y a reflexionar sobre el tema; Weber (1979) definió al estado moderno como monopólico de la violencia legítima a través de la fuerza física, mientras que Pierre Bourdieu acuñó el término de violencia simbólica, que actúa por medio de la cultura y el lenguaje (Fernández, 2005). Por su parte, el filósofo Slavoj Zizek reflexiona sobre las violencias subjetiva y objetiva. La subjetiva es la puramente física, que es considerada en su forma más visible y que es "practicada por un agente que podemos identificar al instante" (2009, p. 9), y la objetiva es la que se sostiene en la normalidad, lo que hace que no sea reconocida fácilmente y, por lo tanto, sea más difícil acabar con ella. Esta última se divide en dos: la violencia simbólica, que se da a través de la construcción del sentido, y la sistémica, que surge como consecuencia "del funcionamiento homogéneo de nuestro sistema económico y político” (p. 10), por ejemplo la pobreza, la desigualdad, los ecocidios.

Desde el enfoque de la Organización Mundial de la Salud (OMS), se construye una de las definiciones más citadas de la violencia, pero insuficiente para el análisis que nos ocupa:

El uso intencional de la fuerza o el poder físico, de hecho o como amenaza, contra uno mismo, otra persona o un grupo o comunidad, que cause o tenga muchas probabilidades de causar lesiones, muerte, daños psicológicos, trastornos del desarrollo o privaciones (Krug et al., 2003, p. 5).

De acuerdo con el organismo internacional, la violencia se clasifica considerando a quien la perpetra y contra quien se ejecuta; desde esta perspectiva puede ser autoinfligida, interpersonal y colectiva; mientras que por su naturaleza se presenta como física, sexual, psíquica, y de privaciones o descuido. Para este artículo se precisa en sus tipologías física y colectiva, que se refiere a "el uso de la violencia como instrumento por parte de personas que se identifican a sí mismas como miembros de un grupo -ya sea transitorio o con una identidad más permanente- contra otro grupo o conjunto de individuos, para lograr objetivos políticos, económicos o sociales" (OMS, 2003, p. 235).

La definición de la violencia vinculada al narcotráfico considerada para esta investigación, se basa en una integración hecha a través de una revisión de literatura: 
Esta violencia es principalmente factual, visible: asesinatos, secuestros, privaciones ilegales de la libertad (acciones de abuso de la fuerza física). Colectiva, supeditada a redes jerarquizadas de traficantes de drogas ilegales -trasnacionales-, que se constituyen como un espécimen del crimen organizado (Sanmartín, 2010), y que buscan ejercer algún tipo de poder (y control), bien sea político, social, territorial, con propósitos de beneficio económico. Aunque es principalmente física, también puede presentarse en su forma simbólica (Bourdieu, 1986) ante sus manifestaciones de terror; y generada por otra de tipo sistémico (Zizek, 2009), con antecedentes de tipo estructural (corrupción, adicciones, pobreza, por ejemplo) (Minor, 2016).

\section{Marco teórico, agenda-setting}

Las noticias presentadas por los diarios cada día representan una selección hecha de un amplio abanico de acontecimientos dados, por lo que editores y reporteros toman aquellos que (suponen) valen la pena ser comunicados (Lippmann, 2003). Es decir, seleccionan algunos aspectos de la realidad, que ordenan jerárquicamente de acuerdo con su relevancia, para luego exponerlos. Asimismo, las noticias son una importante fuente de socialización cotidiana, por lo que la trasmisión de los acontecimientos dados, el lugar y la forma de presentarlos a los ciudadanos, despertarían su interés, contribuirían a la interpretación que se forman de la realidad y, posiblemente, influirían en su toma de decisiones.

Dentro de las teorías de la comunicación la agenda-setting o establecimiento de la agenda, generada por Maxwell McCombs y Donald Shaw en 1972, ha servido de base para la elaboración de estudios sobre las coberturas de diferentes temas de análisis (principalmente de corte político); y plantea que los medios de comunicación instituyen los temas que serán de interés en la sociedad.

El concepto de agenda-setting se estudió inicialmente dentro del contexto tradicional de la comunicación de masas y el comportamiento del votante. Su nombre metafórico proviene de la noción de que los medios masivos de comunicación son capaces de transferir la relevancia de una noticia en su agenda a la de la sociedad (McCombs, 1996, p. 17).

Dicha teoría se desarrolla en dos niveles, en un primer nivel se plantea que los medios señalan en qué se debe pensar (la prominencia del objeto); mientras que en un segundo nivel se considera la transferencia de prominencia del atributo, "nos dicen el cómo pensar", es aquí donde coinciden el establecimiento de la agenda de atributos y el framing, de acuerdo con McCombs et al. (2003). Los autores señalan que una de las virtudes de la teoría de la 
agenda-setting que han impulsado su continuo crecimiento a lo largo de los años es su compatibilidad con diversos conceptos y teorías de la comunicación.

\section{Ruta metodológica: selección temática}

En este apartado se presenta la estrategia metodológica desarrollada para responder a las preguntas establecidas en este artículo de investigación:

- ¿Qué tipo de cobertura informativa sobre la violencia vinculada al narcotráfico realizaron los medios impresos tijuanenses El Mexicano y Frontera en el periodo de septiembre de 2008 a julio de 2011? ¿A qué fuentes se acudió?

- ¿Qué papel jugó el tema de la violencia vinculada al narcotráfico en el contexto general de noticias presentadas por El Mexicano y Frontera durante el periodo de análisis?

- ¿Cuáles son las diferencias de cobertura informativa del tema de análisis presentes en los diarios El Mexicano y Frontera?

Como plataforma metodológica se tomó la propuesta de selección temática de Pablo López (2010), que va dentro de un modelo más amplio de estrategia de encuadre, que tiene su base en la teoría del framing y la agenda-setting. El propósito de analizar la selección temática es determinar una agenda temática especializada que configure un imaginario informativo vinculado al medio, a través de la técnica de análisis de contenido que, como señala José Carlos Lozano (1994), es un instrumento útil para la descripción sistemática y confiable de todo tipo de estudios de cobertura, no sólo desde la perspectiva cuantitativa sino también desde la cualitativa, y se centra en el mensaje comunicativo. Asimismo, Klaus Krippendorff (1990) señala que este método es flexible, y otorga la posibilidad de "formular, a partir de ciertos datos, inferencias reproducibles y válidas que puedan aplicarse a su contexto" (Krippendorff, 1990, p. 28).

Para efectuar el trabajo empírico de esta investigación, se tomó como unidad de análisis las noticias titulares ubicadas en la primera plana de los periódicos El Mexicano y Frontera. ${ }^{25}$ Se estableció un corpus de 126 noticias, por cada uno de los diarios caso de estudio. Esta

25 La noticia de la primera plana "define una manera de ejercer el periodismo y al mismo tiempo se convierte en un estilo propio de afrontar la historia” (Vicent, 2007, SD). http://elpais.com/diario/2007/02/18/sociedad/1171753206_850215.html 
delimitación se llevó a cabo al tomar un mes sí y otro no, dentro del periodo de septiembre de 2008 a julio de 2011, sumando 18 meses, de los cuales se seleccionó una semana completa por cada mes de forma no aleatoria, es decir, siete ejemplares por mes $(18 \times 7=$ 126). Se clasificaron las noticias, sin discriminar el tópico del cual trataban; de esta forma se determinaron los aspectos sobresalientes presentados por cada medio, y se caracterizó así una agenda general que, en conclusión, determinó tres elementos claros: contenido, estructura y estrategia de cobertura mediática. Para este recuento se clasificaron 20 subcategorías temáticas, de las cuales 10 corresponden al tema de análisis de esta investigación, la violencia vinculada al narcotráfico; las otras diez precisan otros temas relevantes para la vida cotidiana de los lectores. El registro se realizó con el programa estadístico Excel.

TABLA 1. TÓPICOS DESGLOSADOS PARA IDENTIFICAR LA SEIECCOÓN TEMÁTCA DE LOS DIARIOS ANAUZADOS. CLASIFICACIÓN DE 20 SUBCATEGORIAS TEMÁTICAS

\begin{tabular}{|l|l|l|l|}
\hline $\begin{array}{l}\text { IN FORM ACIÓN } \\
\text { GE NE RAL }\end{array}$ & \multicolumn{1}{|c|}{ P OLÍTICA } & $\begin{array}{c}\text { VIOLE NCIA VINCU LAD A } \\
\text { AL N ARCOTRÁFICO }\end{array}$ & P OLICÍACA \\
\hline E CON OM ÍA & Migración / frontera & Narcotráfico & Inseguridad ciudadana \\
\hline E D U CACIÓN & Salud & Corrupción asociada al narcotráfico & Seguridad pública \\
\hline $\begin{array}{l}\text { P OĹTICA } \\
\text { IN TE RN ACION AL }\end{array}$ & Deportes & Operativo conjunto BC & Adicciones \\
\hline $\begin{array}{l}\text { P ARTICIP ACIÓN } \\
\text { CIU D AD AN A }\end{array}$ & Cultura & Lucha anticrimen & Derechos humanos \\
\hline
\end{tabular}

FUENTE: MINOR, 2016.

El método de análisis inicia con la revisión sistemática de la muestra mediante la aplicación de una parrilla de análisis de contenido sectorial. La unidad de análisis es el texto escrito y su estructura periodística básica: la noticia, cuerpo, entrada y remate, se incluyen títulos, antetítulos y sumarios. Se plantean seis categorías vinculadas con la definición de la agenda mediática (López, 2010). Fueron analizadas las seis categorías, pero por cuestiones de espacio sólo se desarrollarán las categorías de presencia informativa y clasificación temática en el apartado de resultados. 


\section{Portadas de los casos de estudio: diarios Frontera y El Mexicano}

A continuación se presentan las imágenes de las primeras planas de los diarios tijuanenses que serán objeto de análisis, El Mexicano y Frontera.

IMAGEN 1. PORTADA DE DIARIO FRONIERA, FORMATO TABLOIDE, DE 1 DE OCTUBRE DE 2008.

EN LA PRIMERA PÁGINA SÓLO SE COLOCA EL TTTULAR Y SUMARIOS DE LA NOTIAA, MIENTRAS QUE EN E I INTERIOR DEL DIARIO (PÁGINA 2A, SECCIÓN POUAACA O SECCIÓN TJUANA) SE UBICA LA INFORMACÓN COMPLETA, QUE GENERALMENTE ES BREVE, CON UN MÁXIMO DE OCHO PÁRRAFOS.

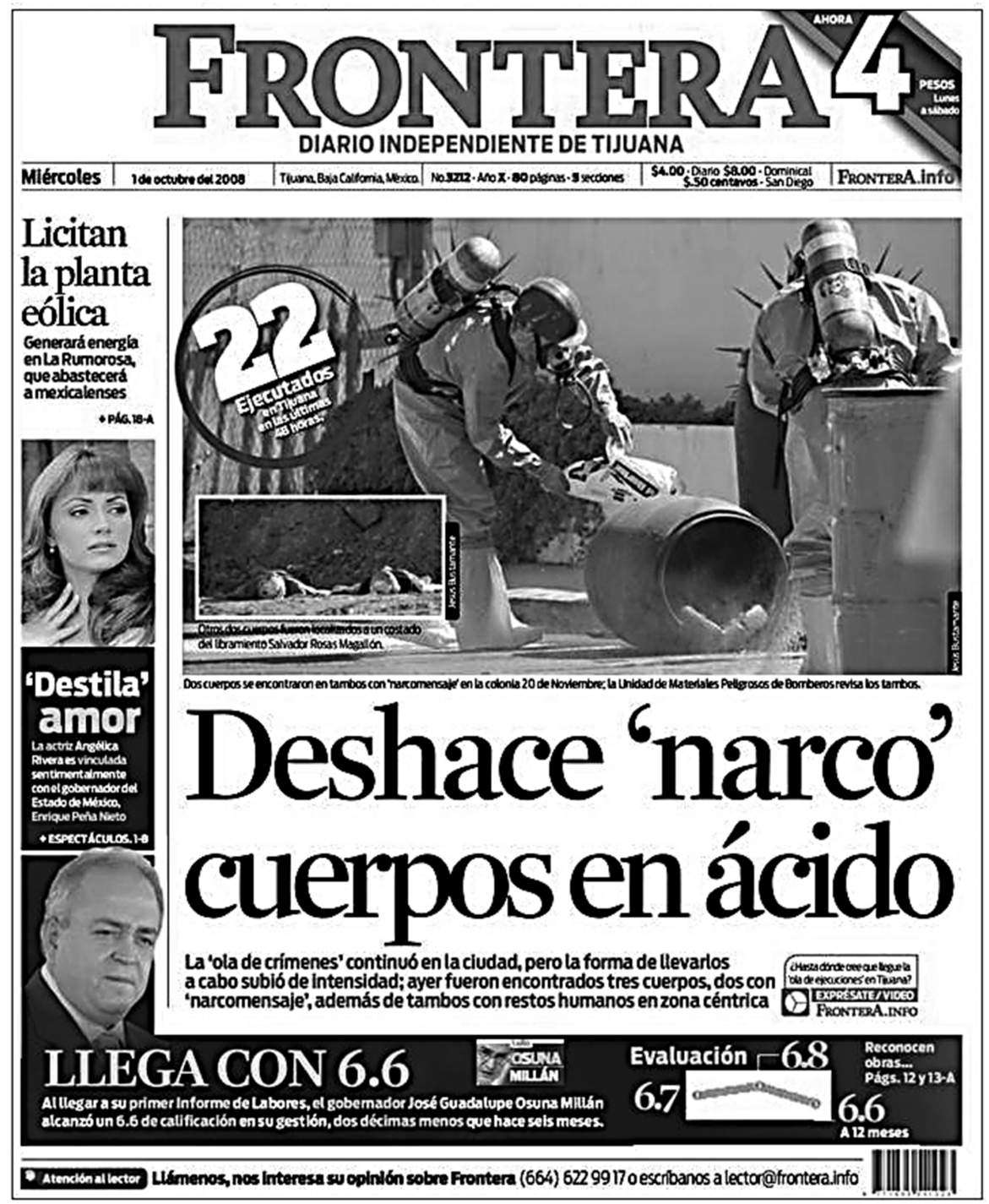


IMAGEN 2. PORTADA ESTÁNDAR DEL PERIÓDICO GENERAUSTA EL MEXICANO, LUNES 4 DE ENERO DE 2010. EN LA PRIMERA PÁGINA SE COLOCA EL ANIETÍTULO, TÍTULO, SUMARIO Y DOS O TRES PÁRRAFOS DE LA NOTICIA, MIENTRAS QUE LA INFORMACIÓN COMPLETA SE UBICA EN LA PÁGINA 3A DE LA SECCOÓN ESTATAL, Y PUEDE ABARCAR HASTA 15 PÁRRAFOS.

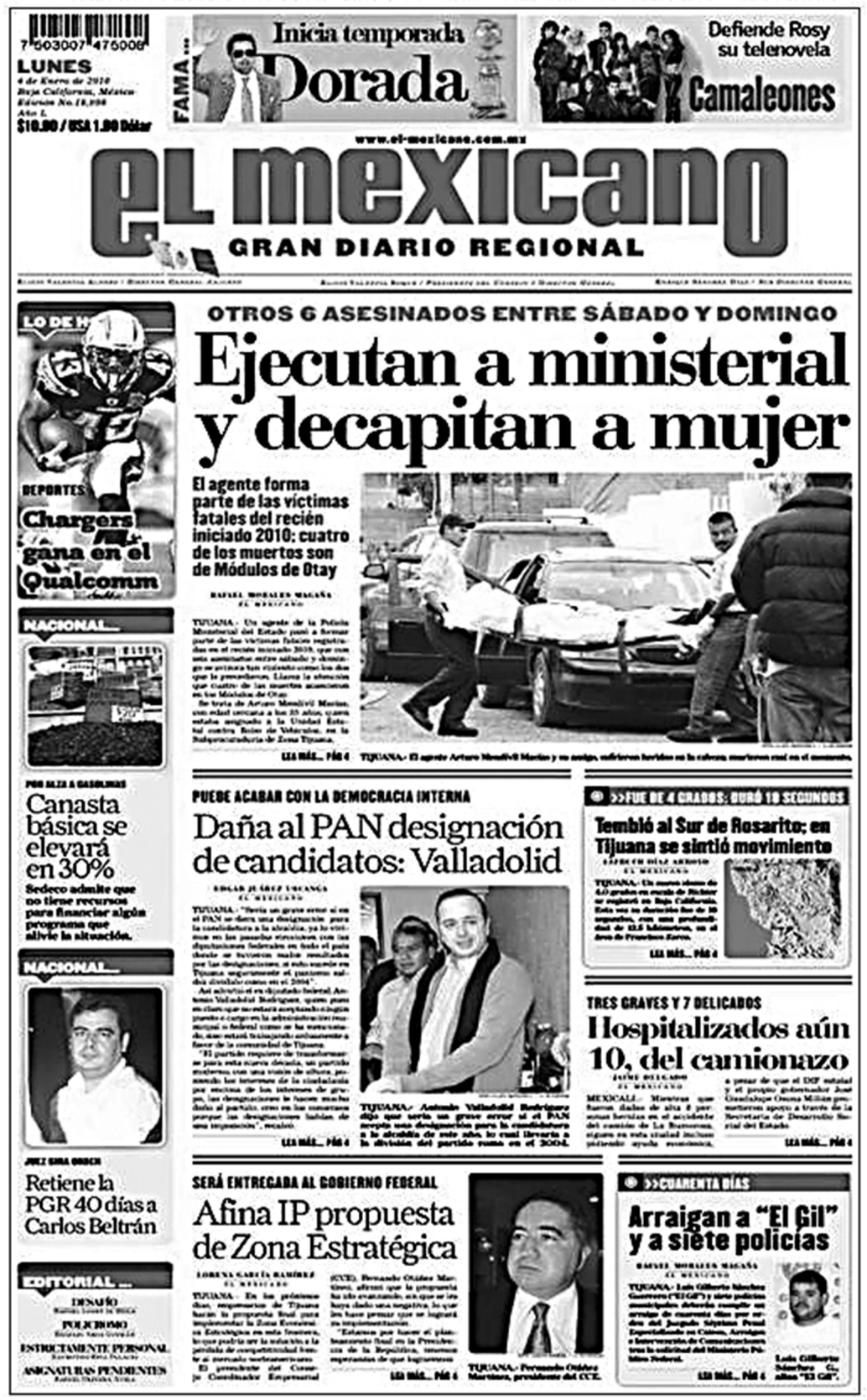


TABLA 2. SE PLANTEAN SES CATEGORÍAS VINCULADAS CON LA DEINICOÓN DE LA AGENDA MEDIÁTCA (LÓPEZ, 2010). SÓLO SE PRESENTARÁN LOS DATOS DE LAS CATEGORÍAS SELECCIONADAS CON COLOR GRIS.

\begin{tabular}{|c|c|c|}
\hline 1 & Presencia informativa & $\begin{array}{l}\text { El objetivo es identificar correctamente la muestra, para el análisis posterior de la } \\
\text { organización discursiva, y precisar la representatividad del tema de análisis: la violen- } \\
\text { cia vinculada al narcotráfico, asimismo, nos permitirá conocer la presencia de otros } \\
\text { temas transversales relevantes. }\end{array}$ \\
\hline 2 & $\begin{array}{l}\text { Jerarquización } \\
\text { informativa }\end{array}$ & $\begin{array}{l}\text { Pretende cuantificar la utilización de dos mecanismos básicos de atribución de rele- } \\
\text { vancia informativa, la ubicación de espacios informativos relevantes y la integración } \\
\text { del texto en algún tipo de cintillo o contenido especial (portada / titular / antetítulo / } \\
\text { sumario / ubicación en interiores / cintillo). }\end{array}$ \\
\hline 3 & Clasificación temática & $\begin{array}{l}\text { "La clasificación temática permite describir una estructura de temas dividida en } \\
\text { varios niveles" (López, 2010: 241). Para desarrollar esta categoría se tomó la pro- } \\
\text { puesta de mapa temático desarrollado por López (2008). Aunque el autor realiza una } \\
\text { proposición compleja dividida en tres niveles, se simplificó para hacerla operativa a } \\
\text { esta investigación. } \\
\text { Primer nivel: Organizaciones temáticas principales. Están formadas por temas } \\
\text { transversales muy cohesionados, con un eje temático compartido y un actor principal } \\
\text { común. Reciben máxima relevancia. } \\
\text { Segundo nivel: Organizaciones temáticas secundarias. Están formadas por temas más } \\
\text { concretos y autónomos entre sí que carecen de lazos importantes compartidos entre } \\
\text { ellos (eje central claro). Estas características les impiden mantener una continuidad } \\
\text { temporal y desarrollar una gran cohesión interna. } \\
\text { Tercer nivel: Su presencia es poco constante o nula en los contenidos. Su importancia } \\
\text { radica en dejar constancia de su aportación cuantitativa. }\end{array}$ \\
\hline 4 & $\begin{array}{l}\text { Definición del actor } \\
\text { informativo }\end{array}$ & $\begin{array}{l}\text { Pretende identificar los principales actores presentes en el discuros periodístico, in- } \\
\text { dicando tanto el área profesional a la que pertenecen (política, economía, sociedad, } \\
\text { seguridad pública, militar, entre otros), como el grado de abstracción con el que se } \\
\text { presentan las fuentes (instituciones, cargos, personas). }\end{array}$ \\
\hline 5 & $\begin{array}{l}\text { Definición de espacio } \\
\text { informativo }\end{array}$ & $\begin{array}{l}\text { Sintetiza las áreas geográficas a las que se refieren las noticias (locales, estatales, } \\
\text { nacionales e internacionales). }\end{array}$ \\
\hline 6 & $\begin{array}{l}\text { Definición del tiempo } \\
\text { informativo }\end{array}$ & $\begin{array}{l}\text { Revisa el tiempo de actualidad y el grado de contextualización informativa que ofrece } \\
\text { el medio. (El momento al que se refiere la nota, día previo, tiempo atrás o a futuro). }\end{array}$ \\
\hline
\end{tabular}

FUENTE: EABORACÓ́N PROPIA CON INFORMACOÓN DE LÓPEZ(2010). 


\section{TABLA 3. FCHA DE LA PARRIШA DE ANÁUSIS DE CONIENIDO PARA LA ETAPA DE SEECCIÓN TEMÁTICA. EABORACOÓN PROPIA CON BASE EN LA PROPUESTA DE LÓPEZ (2008), ADECUADA A ESTE ESTUDIO.}

\begin{tabular}{|c|c|}
\hline \multicolumn{2}{|r|}{ SE LE CCIÓN TE M ÁTICA } \\
\hline \multicolumn{2}{|r|}{$\begin{array}{c}\text { I. DEFINICIÓN DE AGENDA } \\
\text { (PRESENCIA INFORM ATIVA, JERARQUIZACIÓN INFORM ATIVA, CLASIFICIACIÓN TEM ÁTICA) }\end{array}$} \\
\hline 1 & Nombre del diario: E/ Mexicano / Frontera. \\
\hline 2 & Núm. de ejemplar: clasificación de captura. \\
\hline 3 & Fecha de publicación: día/mes/año. \\
\hline 4 & $\begin{array}{l}\text { Título: El titular es la parte principal de enunciación en la estructura de la noticia; debe recoger, en resumen, } \\
\text { los elementos esenciales de la información. Resalta la importancia que para el medio de comunicación tiene la } \\
\text { noticia que publica, que sirve para atraer la atención del elector. (Armentia y Cisneros, 2003). }\end{array}$ \\
\hline 5 & Antetítulo: Complementa al titular, ayuda a explicar brevemente la noticia. (Armentia y Cisneros, 2003). \\
\hline 6 & $\begin{array}{l}\text { Cintillo: Es un elemento que forma parte de la titulación (Armentia y Cisneros, 2003). Su finalidad es promover } \\
\text { en la portada las noticias desarrolladas en las páginas interiores del periódico. Normalmente se compone de } \\
\text { pocas palabras. Se ubica siempre por encima del antetítulo. }\end{array}$ \\
\hline 7 & $\begin{array}{l}\text { Sumario: Es el titular que sirve para llamar la atención sobre aspectos que están contemplados en el cuerpo de la } \\
\text { información, pero que no aparecen de ninguna otra parte del encabezamiento. (Armentia y Cisneros, 2003: 78). }\end{array}$ \\
\hline 8 & $\begin{array}{l}\text { Tema: El argumento principal de cada noticia. Los temas centrales serán clasificados con base en las siguientes } \\
\text { subcategorías: 0) información general, 1) inseguridad ciudadana, 2) narcotráfico, 3) violencia vinculada al } \\
\text { narcotráfico, 4) policiaca, 5) política, 6) economía, 7) políticas de seguridad pública, 8) corrupción policiaca } \\
\text { vinculada al narcotráfico, 9) desarrollo social, 10) adicciones, 11) cultura, 12) operativo militar, 13) salud, 14) } \\
\text { educación, 15) migración ( frontera, 16) lucha anticrimen, 17) derechos humanos, 18) participación ciudadana, } \\
\text { 19) política internacional, 20) deportes. }\end{array}$ \\
\hline 9 & Autor: Reportero del diario que firma la noticia (reportero, agencia, corresponsal). \\
\hline 10 & Página / sección: Ubicación de la noticia, portada y desarrollo en sección interior. \\
\hline 11 & $\begin{array}{l}\text { Género periodístico: Géneros informativos: breves, noticia, entrevista. Géneros interpretativos: reportaje, infor- } \\
\text { mes especiales, crónica. Los géneros de opinión (columnas y editoriales) no se contemplaron. }\end{array}$ \\
\hline 12 & Llamados en interiores: Cintillos, llamados laterales o inferiores especiales de notas a interiores. \\
\hline 13 & $\begin{array}{l}\text { llustraciones y fotografías: la noticia cuenta con fotografía (no se analizará a fondo la imagen, solo se contem- } \\
\text { plará para la jerarquización de la información). } \\
\text { Categorías que profundizan en la caracterización de la agenda mediática (actor, espacio y tiempo informativo). }\end{array}$ \\
\hline \multicolumn{2}{|r|}{$\begin{array}{l}\text { II. CATEGORÍAS QUE PROFUNDIZAN EN LA CARACTERIZACIÓN DE LA AGENDA M EDIÁTICA } \\
\text { (ACTOR, ESPACIO Y TIEM PO INFORM ATIVO) }\end{array}$} \\
\hline 14 & $\begin{array}{l}\text { Actor informativo: Figura principal de la información. Individuos presentes en las noticas que tienen un prota- } \\
\text { gonismo mayor. }\end{array}$ \\
\hline 15 & Espacio: Ubicación de donde se generó la noticia. \\
\hline 16 & npo informativo: Del día, semana, año, de uno a cinco años, más de cinco años. \\
\hline
\end{tabular}

FUENTE: MINOR, 2016. 


\section{Resultados}

\section{Definición de la agenda informativa, El Mexicano y Frontera}

En el periódico El Mexicano se presenta como tema principal, de entre los 20 tópicos delimitados, los de tipo económico. La economía obtuvo en las noticias de portada del diario un $16.67 \%$ del total analizado (21 casos de 126), lo cual se relaciona con la recesión económica internacional cursada en el periodo de análisis. Los siguientes temas relevantes son el narcotráfico, con $14.29 \%$, y la violencia vinculada al narcotráfico, con $13.49 \%$ de apariciones; Seguridad pública 4.76\%, Operativo Conjunto Baja California, corrupción policiaca y lucba anticrimen, estas tres subcategorías cuentan con un 3.96\% cada una; además está inseguridad ciudadana con un $2.38 \%$. Esta cobertura coincide con los acontecimientos violentos dados en Tijuana: enfrentamientos entre los grupos de redes del narco por el poder ante sus divisiones internas, el ataque directo del gobierno federal a los cárteles del narcotráfico y, en un nivel bajo, las estrategias de seguridad pública. Estas subcategorías temáticas se encuentran divididas para estudiarlas con más detalle, de lo contrario habrían mostrado la preponderancia del tema de análisis en las primeras páginas de El Mexicano con $46.83 \%$ de la muestra. Las noticias tipo policiaca gozaron de $12.70 \%$, porcentaje que también es sobresaliente, reflejo del valor noticioso que el periódico le dio a los tópicos que exhiben una ruptura de la normalidad.

Otras temáticas importantes para el desarrollo democrático de los lectores que se vieron rezagadas son política, con sólo $10.32 \%$ de las noticias titulares en la portada; $p$ lítica internacional, 3.17\% (ante la cercanía de Tijuana con Estados Unidos); salud, 2.38\%; educación, $0.79 \%$. Los datos exhiben sólo los acontecimientos sobresalientes del día, y la nula existencia de una agenda definida deliberadamente por el medio de comunicación. El tema adicciones no apareció, y se excluyeron también derecbos bumanos, participación ciudadana y cultura.

En el tabloide Frontera el porcentaje mayor de aparición lo obtuvieron las noticias policiacas (robos, corrupción policiaca y asesinatos no vinculados al narcotráfico a gran escala, motines en penales, tráfico de personas, desastres naturales, accidentes) con $21 \%$ (27 casos), colocándolo como un tema central. El narcotráfico apareció en 18\% ( 23 casos); se trata de detenciones de traficantes, decomisos de armas y estupefacientes, localización de plantíos de mariguana. En tercer lugar se colocó el tema de la violencia vinculada al narcotráfico: asesinatos, secuestros, privaciones ilegales de la libertad, tópico que se evidenció en $15 \%$ (18 casos). ${ }^{26} \mathrm{La}$ inseguridad ciudadana y la corrupción asociada al narco-

26 Es importante mencionar que en los dos diarios, las categorías de narcotráfico y violencia vinculada al narco- 
tráfico obtuvieron $5 \%$ cada una. Seguridad pública, subcategoría con la que busco conocer la difusión de las estrategias y políticas de las autoridades en esta materia, no tiene relevancia, apareció sólo en $2 \%$.

El sentimiento o percepción de inseguridad ciudadana de los tijuanenses no jugó un papel importante para Frontera, sólo 5\%. Asimismo, las estrategias de seguridad, civil y militar no repercutieron como temas centrales de análisis. El Operativo Conjunto Baja California iniciado en 2007 -la salida del Ejército a las calles-no resaltó, y al presentarse la información fue solamente sobre cambios en los altos mandos regionales. Este operativo militar sólo estuvo presente en cuatro ocasiones: $3 \%$. En el caso de la lucba anticrimen como discurso federal encabezado por el presidente Felipe Calderón no hubo ninguna aparición registrada, lo cual nos indica el desdén del medio impreso a la transmisión del discurso oficial-gubernamental.

Ante una cobertura principalmente sobre violencia, los temas que no tenían relación con situaciones policiacas o del narcotráfico ocuparon un espacio secundario de aparición. La subcategoría economía fue poco sobresaliente al contar con 9\% (11 casos). Política destacó como titular en momentos coyunturales electorales, pero no en la presentación de propuestas, sino de resultados en los comicios federales de 2009, locales en 2010, y en 2011 de otros estados del país, que alcanzó 6\%. Temas generales (clima, ecología, comunidad, tráfico) aparecieron en $7 \%$. Educación estuvo presente en $4 \%$. Las noticias sobre salud fueron emitidas principalmente ante el problema de la epidemia de la influenza AH1N1, que fue una contingencia nacional que se presentó durante los primeros meses de 2009, con $2 \%$. Participación ciudadana: $2 \%$. El tema adicciones, con $2 \%$, no destaca como un problema de salud. Deportes, $1 \%$, cuyo motivo fue la llegada del equipo local de futbol, Xolos de Tijuana, a la primera división, algo inusitado hasta ese momento. Derechos bumanos (respeto, violaciones, consecuencias), desarrollo social (pobreza), migración (migrantes, deportaciones, violaciones a los derechos de los migrantes) y cultura no fueron presentados por Frontera en sus titulares de portada dentro de la muestra tomada.

tráfico, aun cuando no eran colocadas en el titular principal de portada, comúnmente se registraban en cintillos, notas inferiores en la primera plana o llamados para interiores, lo cual se observará más adelante. 


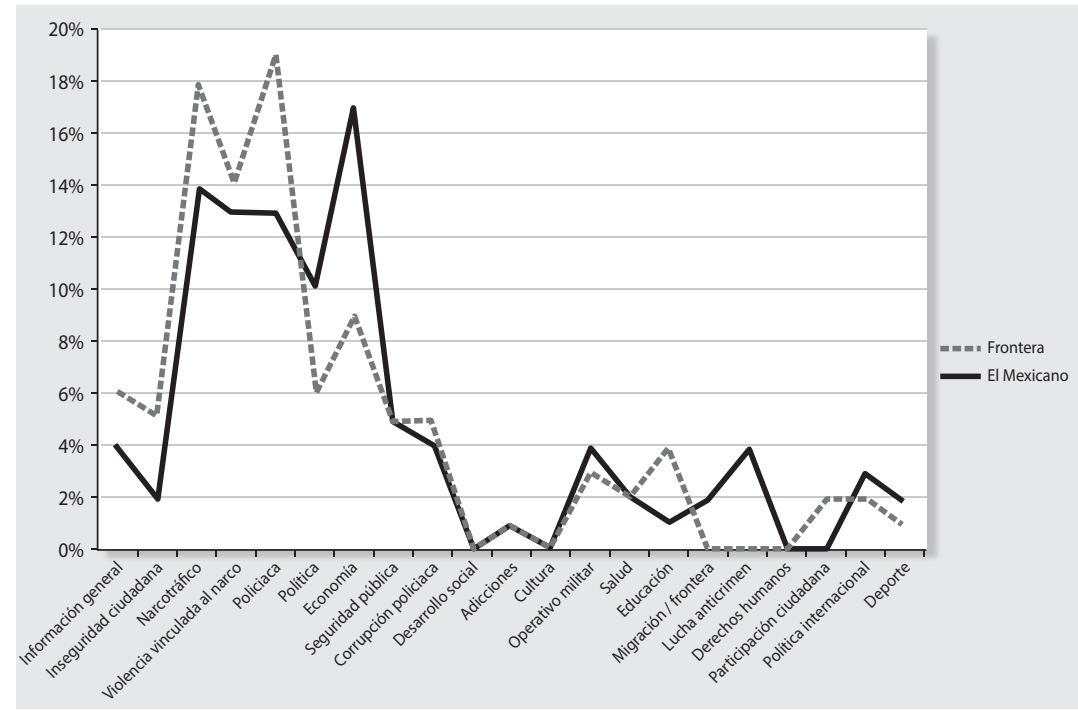

GRÁFICA 1. RRECUENCIA DE APARICÓN DE TEMAS EN LAS PORTADAS DE 日 MEXICANOY FRONIERA, DE ACUERDO CON LA MUESTRA TOMADA DE SEPTIEMBRE DE 2008 A JUNIO DE 2011. EL TOTAL DE LA MUESTRA ES DE 126 PORTADAS PARA CADA PERIÓDICO.

\section{Fuentes: origen de la información publicada}

El Mexicano y Frontera acuden con frecuencia a las fuentes oficiales/legitimadas para obtener la información que requieren para producir las noticias que ofrecen a sus lectores. Los datos de la muestra son los siguientes:

La Procuraduría General de Justicia del Estado de Baja California (PGJE), la Secretaría de Seguridad Pública del Estado (SSP) y la Policía Estatal Preventiva (PEP) sobresalen en puntos porcentuales como fuentes de información para ambos medios impresos con $16 \%$ en Fronteray 15\% en El Mexicano, lo que evidencia una concentración de información por parte del gobierno del estado, que actuaba como administrador (dosificador) de los datos ante los periodistas. El Ejército y la Marina cuentan con un acercamiento similar para ambos medios, de $8 \%$. En cambio, la Secretaría de Seguridad Pública de Tijuana (SSPT) muestra una diferencia notable, Frontera la toma como fuente en 12\%, mientras que El Mexicano en $2 \%$. La Procuraduría General de la República (PGR) y la Policía Federal suman 6\% en Frontera y $7 \%$ en El Mexicano.

La información de sucesos del narcotráfico y violencia vinculada a éste se consigue a través de entrevistas a funcionarios, boletines informativos, extractos de actas policiacas y, 
de manera directa, al acudir al lugar de los acontecimientos y registrar los aspectos observados, entrevistar a testigos, vecinos del lugar; pero principalmente a través de ruedas de prensa, en las que son exhibidos los presuntos delincuentes detenidos y las armas o drogas decomisadas. Este tipo de reporteo sólo provoca una carencia de datos relevantes y da voz a la perspectiva oficial, lo que no ayuda a generar un análisis sobre el fenómeno.

En El Mexicano, 9.52\% de las notas no tienen fuente o no se especifica de dónde surgió la información; ya que se trata principalmente de noticias sobre temas de violencia o de inseguridad se infiere que, ante el riesgo que significa para la fuente otorgar información clasificada, ésta opta por hacerlo de manera anónima o a través de filtraciones. Identificar "quién dice qué" es una cuestión de rigor periodístico, credibilidad y de orientación para el lector, pero algunos medios prefieren omitirlo por seguridad de sus informantes. Por su parte, Frontera sólo cuenta con 3\% de notas sin fuente.

Las dependencias de los tres niveles de gobierno, federal, estatal y municipal, lograron ser un canal de acceso a la información en $17 \%$ para El Mexicano y en 13\% para Frontera. Al ser la economía el tema principal en las portadas de El Mexicano, los organismos empresariales conjuntaron $11 \%$ de apariciones, pero la información económica cuenta también con otro tipo de fuentes: dependencias, especialistas, ciudadanos. Para Frontera, los miembros de la iniciativa privada fueron su fuente sólo en $6 \%{ }^{27}$

Las notas que tuvieron como fuente a académicos, sociedad civil, ciudadanos, organizaciones no gubernamentales (ONG) y asociaciones civiles fueron mínimas: 15\% en Frontera y $10 \%$ en El Mexicano, lo cual muestra el limitado acceso de las "voces alternativas" a los medios. Las voces de las víctimas sobrevivientes y de los familiares de las personas asesinadas, secuestradas o privadas ilegalmente de su libertad se escucharon poco, de no ser para narrar la forma en que pasaron los hechos. A continuación se presentan las estadísticas de forma desglosada.

27 Es extraño que los representantes de la iniciativa privada no aparezcan como fuente de información común en Frontera, al contar con organismos legitimados (Coparmex, Canaco, Canacintra, etc.), peso económico y representación social, líderes de opinión tradicionales en la ciudad. De hecho, han realizado manifestaciones en pro de la paz y campañas de "limpieza" de imagen de Tijuana en Estados Unidos. Esta situación muestra un distanciamiento del medio impreso con un sector representativo. Estos grupos han pedido una disminución en la presentación de noticias policiacas en los medios locales, pues posicionan a Tijuana como una ciudad violenta ante los habitantes de California, que son una importante fuente de ingresos para la región a través del turismo (ejemplar 177, de El Informador de Baja California, 21-02-2013). 
TABLA 4. FRECUENGA DE APARICÓN DE FUENTES EN LAS PORTADAS DE B MEXICANOY FRONTERA, DE ACU EL TOTAL DE LA MUESTRA ES DE 126 PORTADAS PARA CADA DIARIO.

\begin{tabular}{|c|c|c|c|c|}
\hline & \multicolumn{2}{|c|}{ FRON TE RA } & \multicolumn{2}{|c|}{ ELMEXICANO } \\
\hline & NOTAS & $\%$ & NOTAS & $\%$ \\
\hline PGJE / SSP / PEP & 20 & 16 & 18 & 15 \\
\hline Secretaría de Seguridad Pública Tijuana & 15 & 12 & 2 & 2 \\
\hline Iniciativa privada & 7 & 6 & 13 & 11 \\
\hline Extraoficial / No tiene & 4 & 3 & 12 & 10 \\
\hline Ejército / Marina & 10 & 8 & 10 & 8 \\
\hline Ciudadanos / Testigos / Usuarios & 7 & 6 & 3 & 2 \\
\hline Congreso estatal / federal & 2 & 2 & 4 & 3 \\
\hline Dependencias estatales & 5 & 4 & 4 & 3 \\
\hline Dependencias federales & 8 & 6 & 7 & 5 \\
\hline ONG / sociedad civil / sindicatos & 6 & 5 & 6 & 5 \\
\hline Bomberos / Protección civil / Cruz Roja & 3 & 2 & 3 & 2 \\
\hline Gobernador de BC & 1 & 1 & 5 & 4 \\
\hline Gobierno de EE. UU. & 4 & 3 & 7 & 6 \\
\hline Gobierno municipal Tijuana & 4 & 3 & 8 & 6 \\
\hline Partidos políticos / organismos electorales & 4 & 3 & 2 & 2 \\
\hline PGR / SSPF & 8 & 6 & 8 & 7 \\
\hline Presidencia de la república México & 1 & 1 & 3 & 2 \\
\hline Universidades / académicos & 5 & 4 & 4 & 3 \\
\hline \multirow[t]{2}{*}{ Varias } & 12 & 9 & 7 & 4 \\
\hline & 126 & 100 & 126 & 100 \\
\hline
\end{tabular}

FUENTE: MINOR, 2016.

\section{Categoría de clasificación temática en la definición de la agenda, El Mexicano}

Esta categoría se refiere a la frecuencia, relación y descripción de los ejes temáticos presentes en las notas de la muestra en El Mexicano. De acuerdo con Pablo López, ésta "permite describir una estructura temática completa dividida en varios niveles” (2010, p. 241). Para realizarla se tomaron en cuenta sólo las noticias referentes al clúster de la violencia vinculada al narcotráfico, que representan $46.83 \%$ de las notas analizadas (59 de 126 casos). 


\section{TABLA 5. RRECUENCIA SUBCATEGORIA TEMÁTICA DE LA VOLENGA VINCULADA AL NARCOTRÁFICO (46.83\% DE LA MUESTRA) EN EI MEXICANO, DE SEPTIEMBRE DE 2008 A JUUO DE 2011.}

\begin{tabular}{|c|c|c|c|c|}
\hline NIVE L & TE M ÁTICA & DE SCRIP CIÓN & NOTA & $\%$ \\
\hline \multirow[t]{2}{*}{$\begin{array}{l}\text { Primer } \\
\text { nivel }\end{array}$} & Narcotráfico & $\begin{array}{l}\text { Detenciones de traficantes, decomisos de droga a gran escala; inves- } \\
\text { tigaciones. Los actores principales son los supuestos delincuentes } \\
\text { miembros de redes de narcotráfico. } \\
\text { «Sicarios de "El Muletas" tenían "cuartel militar"»(02/11/2010) }\end{array}$ & 18 & $31 \%$ \\
\hline & $\begin{array}{l}\text { Violencia/ } \\
\text { Narcotráfico }\end{array}$ & $\begin{array}{l}\text { Asesinatos o atentados, secuestros, privaciones a la libertad con } \\
\text { posible relación con las redes del narcotráfico. Se presenta como la } \\
\text { exacerbación de la violencia. Ataques directos (asesinatos) de miem- } \\
\text { bros del narco a policías en Tijuana. El Mexicano exhibe la sumatoria } \\
\text { de los asesinatos como el acontecimiento. } \\
\text { «580 ejecutados; por narcomenudeo } 60 \% »(22 / 09 / 2010)\end{array}$ & 17 & $29 \%$ \\
\hline \multirow[t]{4}{*}{$\begin{array}{l}\text { Segundo } \\
\text { nivel }\end{array}$} & $\begin{array}{l}\text { Seguridad } \\
\text { pública }\end{array}$ & $\begin{array}{l}\text { Las estrategias de seguridad pública que no involucran las actividades } \\
\text { de las fuerzas militares en la ciudad. } \\
\text { «Avala Alcalde "Tiren a matar"»(27/09/2009) }\end{array}$ & 6 & $10 \%$ \\
\hline & $\begin{array}{l}\text { Corrupción } \\
\text { policiaca }\end{array}$ & $\begin{array}{l}\text { Los vínculos entre las redes del narcotráfico y los miembros de las } \\
\text { diferentes corporaciones policiacas. Casos de detenciones de policías } \\
\text { municipales y estatales (principales actores) relacionados con activi- } \\
\text { dades de las redes de los traficantes de drogas. } \\
\text { «Detiene el ejército a jefes policiacos» (11/11/2008) }\end{array}$ & 5 & $8 \%$ \\
\hline & $\begin{array}{l}\text { Operativo } \\
\text { militar }\end{array}$ & $\begin{array}{l}\text { Acciones de gobierno establecidas a partir de } 2007 \text { como parte de la } \\
\text { estrategia anticrimen propuesta por el gobierno federal, basada en } \\
\text { desplegar fuerzas militares en Tijuana, Baja California. } \\
\text { «Ningún cártel retomará BC ni Tijuana» (27/05/2009) }\end{array}$ & 5 & $8 \%$ \\
\hline & $\begin{array}{l}\text { Lucha } \\
\text { anticrimen }\end{array}$ & $\begin{array}{l}\text { Lucha anticrimen es parte del discurso del gobierno federal y estatal, } \\
\text { que realizan para detener las redes del crimen organizado, entre ellas } \\
\text { el narcotráfico como parte de la estrategia establecida por el entonces } \\
\text { presidente Felipe Calderón, al iniciar su mandato en } 2006 \text {. } \\
\text { «BC, ejemplo de lucha anticrimen» (06/03/2009) }\end{array}$ & 5 & $8 \%$ \\
\hline \multirow[t]{4}{*}{$\begin{array}{l}\text { Tercer } \\
\text { nivel }\end{array}$} & $\begin{array}{l}\text { Inseguridad } \\
\text { pública }\end{array}$ & $\begin{array}{l}\text { La inseguridad ciudadana que vive la población y que se refleja a través } \\
\text { de movilizaciones, de cambios en la vida cotidiana (incremento de } \\
\text { acciones de seguridad privada, dejar de realizar actividades cotidianas). } \\
\text { «Preocupa el nivel de secuestros: IP» (21/09/2008) }\end{array}$ & 3 & $5 \%$ \\
\hline & Adicciones & $\begin{array}{l}\text { Consumo de drogas en Tijuana, manifestado como un problema de } \\
\text { salud amplio, o a través de medidas de prevención }\end{array}$ & 0 & $0 \%$ \\
\hline & $\begin{array}{l}\text { Derechos } \\
\text { humanos }\end{array}$ & $\begin{array}{l}\text { Denuncia, defensa, prevención de violaciones a los derechos humanos } \\
\text { en asuntos relacionados con la lucha contra el narcotráfico o en } \\
\text { general de cualquier tipo. }\end{array}$ & 0 & $0 \%$ \\
\hline & Total general & & 59 & $100 \%$ \\
\hline
\end{tabular}

FUENTE: MINOR, 2016. 


\section{Categoría de clasificación temática en la definición de la agenda, Frontera}

Para realizar esta categoría, en Frontera se consideraron sólo las noticias referentes al clúster de violencia vinculada al narco, que representan $48.41 \%$ de las notas analizadas (61 de 126).

\section{TABLA 6. RRECUENCA SUBCATEGORÍA TEMÁTICA DE LA VOLENAA VNCULADA AL NARCOTRÁFICO (48.41\% DE LA MUESTRA) EN FRONIRAA, DE SEPTIEMBRE DE 2008 A JUUO DE 2011.}

\begin{tabular}{|c|c|c|c|c|}
\hline NIVEL & TE M ÁTICA & DE SCRIP CIÓN & NOTA & $\%$ \\
\hline \multirow[t]{2}{*}{$\begin{array}{l}\text { Primer } \\
\text { nivel }\end{array}$} & Narcotráfico & $\begin{array}{l}\text { Detenciones de traficantes, decomisos de droga a gran escala, juicios, } \\
\text { investigaciones. Los actores principales son los supuestos delincuen- } \\
\text { tes mientras de redes de narcotráfico, líderes de los cárteles de la } \\
\text { droga y miembros en diferentes eslabones de la cadena. } \\
\text { «"Clonan" sicarios autos de militares» (02/11/2009) }\end{array}$ & 23 & $36.5 \%$ \\
\hline & $\begin{array}{l}\text { Violencia/ } \\
\text { Narcotráfico }\end{array}$ & $\begin{array}{l}\text { Asesinatos o atentados, secuestros, privaciones a la libertad con posi- } \\
\text { ble relación con las redes del narcotráfico. Actores presentes: víctimas } \\
\text { y victimarios. } \\
\text { «Rafaguean a una mujer y a su nieto» }(13 / 07 / 2010)\end{array}$ & 18 & $28.5 \%$ \\
\hline \multirow[t]{4}{*}{$\begin{array}{l}\text { Segundo } \\
\text { nivel }\end{array}$} & $\begin{array}{l}\text { Seguridad } \\
\text { pública }\end{array}$ & $\begin{array}{l}\text { Las estrategias y actividades de seguridad pública que no involucran } \\
\text { las actividades de las fuerzas militares en la ciudad, pero que tienen } \\
\text { relación con la violencia vinculada al narcotráfico. } \\
\text { «Militares dirigirán policía Municipal en la Zona Centro» } \\
(18 / 03 / 2009)\end{array}$ & 6 & $9.52 \%$ \\
\hline & $\begin{array}{l}\text { Corrupción } \\
\text { policiaca/ } \\
\text { narcotráfico }\end{array}$ & $\begin{array}{l}\text { Los vínculos entre las redes del narcotráfico y los miembros de las } \\
\text { diferentes corporaciones policiacas. Casos de detenciones de policías } \\
\text { municipales y estatales (principales actores) relacionados con activida- } \\
\text { des de las redes de los traficantes de drogas. } \\
\text { «Retiene ejército a } 16 \text { municipales» (26/03/2009) }\end{array}$ & 6 & $9.52 \%$ \\
\hline & $\begin{array}{l}\text { Inseguridad } \\
\text { ciudadana }\end{array}$ & $\begin{array}{l}\text { La inseguridad ciudadana que vive la población y que se refleja a } \\
\text { través de movilizaciones, de cambios en la vida cotidiana (incremen- } \\
\text { to de acciones de seguridad privada, dejar de realizar actividades } \\
\text { cotidianas). } \\
\text { «Oculta Estado información de inseguridad» (01/07/2011) }\end{array}$ & 5 & $7.93 \%$ \\
\hline & $\begin{array}{l}\text { Operativo } \\
\text { militar }\end{array}$ & $\begin{array}{l}\text { Acciones de gobierno establecidas a partir de } 2007 \text { como parte de la } \\
\text { estrategia anticrimen propuesta por el gobierno federal, basada en } \\
\text { desplegar fuerzas militares en Tijuana, Baja California. } \\
\text { «Va Duarte Múgica a Región Militar 2» (21/11/2010) }\end{array}$ & 4 & $6.34 \%$ \\
\hline
\end{tabular}




\begin{tabular}{|c|c|c|c|c|}
\hline NIVEL & TE M ÁTICA & DE SCRIP CIÓN & NOTA & $\%$ \\
\hline \multirow[t]{4}{*}{$\begin{array}{l}\text { Tercer } \\
\text { nivel }\end{array}$} & Adicciones & $\begin{array}{l}\text { Consumo de drogas manifestado como un asunto estadístico en } \\
\text { Frontera. } \\
\text { «Es segundo BC, pero en adicción» (21/09/2008) }\end{array}$ & 1 & $1.58 \%$ \\
\hline & $\begin{array}{l}\text { Lucha } \\
\text { anticrimen }\end{array}$ & $\begin{array}{l}\text { Lucha anticrimen es parte del discurso del gobierno federal y estatal, } \\
\text { que realizan para detener las redes del crimen organizado, entre ellas } \\
\text { el narcotráfico, como parte de la estrategia establecida por el enton- } \\
\text { ces presidente Felipe Calderón, al iniciar su mandato en } 2006 \text {. }\end{array}$ & 0 & $0 \%$ \\
\hline & $\begin{array}{l}\text { Derechos } \\
\text { humanos }\end{array}$ & $\begin{array}{l}\text { Denuncia, defensa, prevención de violaciones a los derechos humanos } \\
\text { en asuntos relacionados con la lucha contra el narcotráfico o en } \\
\text { general de cualquier tipo. }\end{array}$ & 0 & $0 \%$ \\
\hline & Total general & & & $100 \%$ \\
\hline
\end{tabular}

FUENTE: MINOR, 2016.

\section{Análisis y discusión: contenido, estructura y estrategia mediática}

Las coberturas emprendidas por los diarios casos de estudio, El Mexicano y Frontera, sobre la violencia vinculada al narcotráfico en Tijuana muestran una prioridad cuantitativa en el abordaje de este tema en sus titulares de primera página. Esta información se desarrolló con base en los formatos de nota informativa ${ }^{28}$ y nota roja, siguiendo la lógica periodística de los "valores noticiosos" que tradicionalmente se estilan en esta tipología, como los "aspectos negativos de la realidad" (Cervantes, 1996).

Se reconoce el interés público del tópico, pero se critica un abordaje trivial (con titulares redactados con frases llamativas y "lugares comunes", fórmulas repetitivas o clichés, por ejemplo) y que, como contenido de "nota roja", no estuviera colocado exclusivamente en su propia sección sobre seguridad pública, en el interior del diario $;{ }^{29}$ discriminando así otros enfoques y otras temáticas, también de amplia relevancia social: política, educación, salud,

28 La información es presentada bajo el género de noticia (El Mexicano 98\%, Frontera 94\%), es decir, no presentan crónicas o reportajes especiales.

29 Llama la atención que las noticias sobre narcotráfico y violencia vinculada al narcotráfico anunciadas en el titular de Frontera, en un principio de la muestra no aparecieron dentro de la "parcela" policiaca, sino que cobraron gran interés para el medio de comunicación y saltaron a otras secciones, como Tijuana o información general. Mientras que El Mexicano presenta todas sus noticias titulares de portada completas en la página 4 de la sección Tijuana. 
cultura, participación ciudadana, derechos humanos. Esto evidencia que no existió una agenda plural, planeada y propositiva.

Los diarios presentaron un seguimiento cronológico de los acontecimientos espontáneos y programados, que se vinculan con situaciones coyunturales, pero sin contextualizarlos. Se trata principalmente de los hechos, o de su seguimiento básico; de información consultada en fuentes "legitimadas": gobierno, Ejército, empresarios. Es así que las noticias analizadas no permitieron ampliar la visión del fenómeno y limitaron al lector a una realidad representada de 90 grados: la contención y desarticulación de las redes de traficantes a través de la exhibición de los presuntos delincuentes miembros de algún cártel, escoltados por policías y militares armados, mostrando la droga o armas decomisadas, es decir, la versión oficial sobre los sucesos.

Se reconstruyeron los discursos oficiales/autoritarios basados en el desorden (anomia) y la necesidad de orden (control), de esta forma se legitimarían las acciones gubernamentales y se trivializaría el fenómeno, reduciéndolo a una dimensión mínima. Una estrategia clara de comunicación pública de las autoridades. Se omitió la visión de expertos, ciudadanos, asociaciones civiles y organismos públicos con perspectiva de derechos humanos; mientras la "pacificación de Tijuana" era criticada por dejar de lado estos derechos constitucionales en las estrategias de seguridad pública y de contención de la violencia.

También se representó la violencia a través de los delitos de alto impacto por medio de una descripción breve (y el uso del lenguaje) del parte policiaco que se acopla perfectamente con la estructura periodística de pirámide invertida: ¿Qué? (descripción del suceso o delito), ¿quién? (las personas atacadas -nombres, edades, o entre qué edades posibles, descripción física de la víctima o atacante, entre otros elementos-), ¿cómo? (evidencias que son referidas con precisión, ubicación de casquillos, tipos de armas utilizadas), ¿cuándo? (momento en el que se dio el suceso), ¿¿ónde? (el sitio donde se dieron los hechos), y¿̇por qué?, que en realidad no explica nada (si es que se puede saber el móvil posible). En las portadas de los diarios se difundió lo cotidiano de la muerte, a través de las estadísticas, que en medio de su imprecisión generan mayor inseguridad.

La cobertura de cada periódico muestra una forma particular de "abarcar" la realidad. El Mexicano presenta a sus lectores una diversidad de contenidos limitada; se trata de una estrategia reactiva a los acontecimientos, de perspectiva oficial y de espacio accesible sólo a grupos hegemónicos. De forma independiente -de 20 temáticas consideradas-, la economía ocupa el primer sitio, mientras que en sumatoria las noticias sobre el tema de análisis llegan a $46.8 \%$, dando una cobertura sobre el narcotráfico oficial, reproduciendo el discurso del presidente de la República, Felipe Calderón Hinojosa, y el gobernador de Baja California, para establecer el éxito de sus estrategias de seguridad (Operativo Conjunto Tijuana). 
Y, con respecto a la violencia, la presenta como el "desbordamiento" incontrolable: “Crimen, desatado; otros 7 ejecutados" (08/01/2010).

El periódico Frontera es considerado un diario generalista, sin embargo este análisis lo redefine como un periódico con una fuerte tendencia al periodismo popular, al colocar en sus portadas aquellas noticias que rompen con la normalidad de la ciudad; se trata de su apuesta principal para atraer lectores. Las noticias de narcotráfico, narcoviolencia ( $48.41 \%)$ y nota policiaca (en general $21.42 \%$ ) ocupan un espacio preponderante para el medio (en suma, $69.88 \%$ ), de esta forma se expresa lo cotidiano del delito en primera página. Frontera puede considerarse un diario comercial (regido por el mercado, Hughes, 2009) que se define por su agenda "roja", que no aporta (casi) contenidos alternativos a la violencia física. ${ }^{30} \mathrm{El}$ narcotráfico se presenta como la desarticulación de sus redes, a través de las detenciones de los miembros de células de algún cártel, resaltando estructuras y personalizando liderazgos: "Cae un primo del 'Gordo' Villareal” (11/09/2010). La violencia vinculada al narcotráfico es condensada en tiempo y cantidad: "Ejecutan a 5 en 24 horas" (15/05/2010).

\section{Conclusiones}

En un momento coyuntural de violencia desbordada en Tijuana (2008-2011). Las agresiones físicas históricas hacia los periodistas por parte del narcotráfico (asesinatos y atentados) y el riesgo presente de cumplir con su misión en un entorno hostil generaron un ejercicio de periodismo pragmático. El Mexicano y Frontera establecieron una especie de periodismo precavido (Rodelo, 2008), mediado por el mercado y de autoprotección; lo cual agrede directamente la libertad de expresión y el derecho al acceso a la información pública de sus lectores en particular y de la ciudadanía en general.

El ambiente de censura no evitó que los medios hablaran del crimen organizado y las redes del tráfico de drogas ilegales, al menos superficialmente y desde la perspectiva oficial, ni que colocaran el tema de análisis como su primera apuesta editorial. Haciendo a un lado el ejercicio de un periodismo ciudadano, libre y con investigación, dieron un seguimiento de los hechos a través de la nota roja o policiaca, que por su atractivo noticioso "sí vende" (Morales, 2008, SD). Lo interesante superó a lo importante.

El escenario de violencia vinculada al narcotráfico se complejizó aún más con la instauración de la violencia legítima (Weber, 1979) por parte de las instituciones de los tres

30 De esta manera se puede señalar una transición del periodismo cívico establecida por Hughes (2009) a un periodismo mercantil, también de acuerdo con las categorías establecidas por la investigadora. 
niveles de gobierno a través del "Operativo Conjunto Tijuana"; 31 factores que constituyeron las temáticas cotidianas en la sociedad, como acontecimientos y como discursos, que luego fueron seleccionados y reproducidos por El Mexicano y Frontera. Se presentó así un sistema híbrido de periodismo (Hughes, 2009): autoritario y regido por el mercado. De esta forma, los medios de comunicación desvirtuarían el carácter de los acontecimientos (Waisbord, 2000), lo cual va en contra del principio ético establecido por la Unesco que señala que "la información en periodismo se entiende como bien social y no como un producto" 32 .

$\mathrm{El}$ análisis de contenido de las noticias realizado muestra que el tema de la violencia vinculada al narcotráfico (como un conglomerado general) estuvo ampliamente presente en los titulares de la portada. Tanto El Mexicano como Frontera coinciden en efectuar una cobertura reactiva, circunstancial, acrítica, que limita a los lectores las posibilidades de acceso al conocimiento necesario para entender un fenómeno trasnacional con repercusiones locales. Los diarios casos de estudio no proporcionaron herramientas para generar un debate sobre el fenómeno que se presentó durante el periodo de análisis ni sobre sus repercusiones sociales (presentes y futuras), al no transmitir temáticas plurales y voces alternativas a las oficialmente legitimadas. Su abordaje se basa en presentar los hechos tal cual parecen ser, con información tomada del parte policiaco, de la declaración de un funcionario (a veces de manera anónima) o de una rueda de prensa.

De esa manera que no es posible que los lectores logren identificar más allá de la violencia evidente, la puramente física (subjetiva); por lo que, al no reconocer las violencias sistémica y simbólica -objetivas- (que se mantienen a pesar de la disminución temporal de los asesinatos en 2011), es imposible que puedan mejorar su entorno, influir en la toma de decisiones de políticas públicas que fomenten la pazy disminuyan la inseguridad ciudadana. En contraste, ante las deficiencias temáticas y de contenido, los lectores podrían naturalizar el uso de la fuerza y las estrategias de militarización como el tratamiento ante la problemática, y dejar de lado, por ejemplo, aspectos como la prevención de delitos, de adicciones y de violaciones a los derechos humanos, o la cultura de la legalidad; enfocándose al control y contención de una violencia intermitente que, en 2015 y lo que va de 2016, regresó a niveles de 2010, su punto más álgido.

31 Se aclara que este artículo no critica el “Operativo Tijuana”, sino la comunicación pública que se generó sobre éste, tanto en los medios de comunicación, como en las estrategias gubernamentales.

32 De acuerdo con el Código Internacional de Ética Periodística de la Unesco, el periodismo ético no sólo mantiene la independencia respecto de sus fuentes y los poderes, también respeta una gama de derechos fundamentales de los ciudadanos, no mercantiliza la información, fomenta la paz y la democracia (UNESCO, 1983). 


\section{Referencias}

Amnistía Internacional (2012). Culpables conocidos, víctimas ignoradas. Tortura y maltrato en México. Informe 2012, Amnistía Internacional. Madrid: EDAI.

Armenta, J. \& Cisneros, J. (2003). Fundamentos de periodismo impreso. Barcelona: Ariel.

Artículo 19 (2012). Silencio forzado. El Estado, cómplice de la violencia contra la prensa en México. Informe México 2011. Artículo 19, México, D. F. marzo 2012.

Astorga, L. (2012). El siglo de las drogas. El narcotráfico, del porfiriato al nuevo milenio. México: Grijalva-Proceso.

Astorga, L. (1996). Mitología del "narcotraficante” en México. México: Plaza y Valdés.

Astorga, L. \& Shirk, D. (2010). Drug Trafficking Organizations and Counter-Drug Strategies in the U.S.-Mexican Context. En Evolving Democracy. Center for U.S.-Mexican Studies, UC San Diego. Recuperado de http://escholarship.org/uc/item/8j647429.

Blancornelas, J. (2006). El cartel. Los Arellano Félix: la mafia más poderosa en la bistoria de América Latina. México: Randon House Mondadori.

Bonilla, J. (2002). Periodismo, guerra y paz. Campo intelectual periodístico y agendas de la información en Colombia. Signo y Pensamiento, Vol. XXI, Núm. 40, 53-71. Colombia: Pontificia Universidad Javeriana.

Bourdieu, P. (1986). Espacio social y poder simbólico. Texto de la conferencia pronunciada en la Universidad de San Diego en marzo de 1986. Recuperado de http://www.pueg.unam.mx/ diplomado/images/modulo_1/sesion_2/Pierre_Bourdieu_Espacio_social_y_poder_simbolico.pdf.

Casillas, D. (2012) Reconoce gobierno 47 mil 515 muertes ligadas al narco. En Animal Político. Recuperado de http:/www.animalpolitico.com/2012/01/crecen-11-homicidios-relacionados-con-el-narco-pgr.

CEESEM (2009). Contrastes en los indicadores de cruces fronterizos en puertos de B.C. En Gaceta Económica, año 7, Núm. 343, 4. Mexicali, viernes 30 de enero de 2009.

Committee to Protect Journalists (CPJ) (2010). Silence or death in Mexico's press. Crime, violence, and corruption are destroying the country's journalism. Committee to Protect Journalists.

Cervantes, C. (1996). "Valores noticiosos en el periodismo televisivo de nota roja. Búsqueda articulada de indicadores empíricos”, Comunicación y Sociedad 25/26, 89-137, Guadalajara: DE SC, Universidad de Guadalajara, septiembre 1995- abril 1996.

DOF (2009). Constitución Política de los Estados Unidos Mexicanos. Última reforma publicada en el Diario Oficial de la Federación el 24-08-2009. Recuperado de www3.diputados.gob.mx/ camara/content/download/.../Constitucion.pdf(9/junio/2011).

Escalante, F. (2011). Homicidios 2008-2009. La muerte tiene permiso. Revista Nexos, núm. 398, enero de 2011.

Fernández, J. (2005). La noción de violencia simbólica en la obra de Pierre Bourdieu: una aproximación crítica. Cuadernos de trabajo social, vol. 18, 7-31. Universidad Complutense de Madrid. 
Gomis, L. (1991). Teoría del periodismo. Cómo se forma el presente. Barcelona: Paidós Comunicación.

Hernández, M. (2011) "El periodismo mexicano en estado de emergencia: hacia el debate necesario”, Revista Mexicana de Comunicación. Versión en línea: http://mexicanadecomunicacion. com.mx/rmc/2011/02/28/periodismo-y-violencia-hacia-un-debate-necesario/\#axzz1UfrotMbM.

Hernández, M. \& Rodelo, F. (2010). Dilemas del periodismo mexicano en la cobertura de la guerra contra el narcotráfico: ¿periodismo de guerra o de nota roja? En Z. Rodríguez (Coord.). Entretejidos comunicacionales (pp. 193-228). Guadalajara, México: Universidad de Guadalajara.

Hughes, S. (2009). Redacciones en conflicto. El periodismo y la democratización en México. México: Porrúa/UdeG.

Imbert, G. (1992). Los escenarios de la violencia. Barcelona: Icaria Editorial.

Krippendorf, K. (1990) Metodología de análisis de contenido, Teoría y práctica. Paidós. Barcelona.

Krug, E. et al. (2003). Informe mundial sobre la violencia y la salud. Organización Panamericana de la Salud/Organización Mundial de la Salud. Washington D. C.: OPS.

Lippmann, W. (2003). La opinión pública. Madrid: Cuadernos de Langre.

López, P. (2010). "Nuevas vías para el estudio el framing periodístico: la noción de estrategia de encuadre”. Pablo. Universitat Jaume 1 (Castellón, España).

López, P. (2008). Pensamiento crítico y procesos de construcción de agenda - framing Lemonde Diplomatique (edición española) (1995-206). Revista de Economía Política de las Tecnologías de Información y Comunicación, vol. X, núm. 2, may-ago, 2008.

López, S. (2009). Medios de comunicación y violencia social en Tijuana. En S. López (Coord.). Diagnóstico sobre la realidad social, económica y cultural de los entornos locales para el diseño de intervenciones en materia de prevención y erradicación de la violencia en la región norte: el caso de Tijuana, Baja California. Recuperado de http://www.incidesocial.org. Fecha de consulta: 28 de octubre de 2010.

Lozano, J. (2004). La investigación sobre los mensajes comunicacionales en México: 1990-2002. Anàlisi: Quaderns de comunicació i cultura, no. 31, 149-162.

Lozano, J. (1994). Hacia la reconsideración del análisis de contenido en la investigación de los mensajes comunicacionales, Comunicación y Sociedad, pp. 135-157. Universidad de Guadalajara.

McCombs et al. (2003). Establecimiento de la 'agenda de atributos' en las elecciones generales españolas de 1996. En M. McCombs y I. Luna (Eds.), Agenda-Setting de los medios de comunicación. México: Universidad Iberoamericana.

McCombs, M. (1996). Influencia de las noticias sobre nuestra imagen del mundo”. En J. Bryant y D. Zillmann (Comps.), Los efectos de los medios de comunicación. Investigaciones y teorías (pp. 1334). Barcelona: Paidós.

MEPI (2010). México: la nueva espiral del silencio. La relación entre la narco-violencia y los medios. Recuperado de http://www.fundacionmepi.org/investigaciones/la_nueva_espiral_del_silencio.

MEPI (2011). Autocensura en México 2011. Fundación MEPI, Tecnológico de Monterrey Campus Ciudad de México. www.fundaciónmepi.org 
Minor, M. (2016). Cobertura y tratamiento informativo de la violencia vinculada al narcotráfico en Tijuana: Estrategias de encuadre para su interpretación. El caso de los periódicos tijuanenses ElMexicano y Frontera (2008-2011). Tesis para obtener el grado de Maestra en Comunicación. Universidad de Guadalajara, CUCSH.

MPM (2009). Medios impresos. Edición 202. Mayo. México: Medios Publicitarios Mexicanos. MPM (2000). Medios impresos. Edición 165. Febrero. México: Medios Publicitarios Mexicanos. Morales, J (2008). Reporting in Mexico, a Dangerous Assignment: Murder and Impunity against the Press. En video, The Woodrow Wilson Center's Mexico Institute and the Committee to Protect Journalists (2008). Washington, D. C. Recuperado de https://www.youtube.com/watch?v=7uMbhFWVSFI.

Navarro, A. (2008). La resistencia a la censura. En Libertad de expresión, poderes paralelos 2007. Centro de Periodismo y Ética Pública.

Nívea, P. (1994). Elementos para una teoría de periodismo sensacionalista. Comunicación y Sociedad, núm. 21, 137-159.

Norzagaray, M. (2010). El narcotráfico en México desde el discurso oficial. Un análisis de los sexenios comprendidos en el periodo 1988-2000. Tesis para obtener el grado de Maestro en Ciencias Sociales. Flacso. México.

Núñez, J. (2011). Violencia y periodismo en México. Un acercamiento desde la ética. Revista Mexicana de Comunicación. Año 24, edición 128. Octubre-diciembre 2011. 19-24.

OPS (2012). Salud en las Américas. México. Organización Panamericana de la Salud. Recuperado de http://www.paho.org/saludenlasamericas/index.php?id=71\&option=com_content.

OMS (2003). Informe mundial sobre la violencia y la salud. Krug, E. et al. (Eds.). Organización Mundial de la Salud. Washington, D.C.

Ovalle, L. (2006a) Entre la indiferencia y Satanización. Representaciones del Narcotráfico. Departamento de Editorial Universitaria. Universidad Autónoma de Baja California (UABC). Mexicali. B.C.Ovalle, L. (2007). Ajustes de cuentas. Muertes violentas y narcotráfico en Baja California. Revista de Ciencias Sociales Arenas. Universidad de Sinaloa. Núm. 10.

Petrich, B. (2011). Torturas y violación de derechos, en supuesta pacificación de Tijuana hecha por Leyzaola. La Fornada. Recuperado de http://www.jornada.unam.mx/2011/05/19/index. php? section $=$ politica\&article $=004 \mathrm{n} 1$ pol.

Relly, E. \& González, B. (2015). Silenciar el norte: estudio de las influencias ejercidas sobre los periodistas en los estados fronterizos. En Del Palacio (Coord.), Violencia y periodismo regional en México. México: Juan Pablos Editor.

Reguillo, R. (2011). La narcomáquina y el trabajo de la violencia: Apuntes para su decodificación. Recuperado de http://hemisphericinstitute.org/hemi/es/e-misferica-82/reguilloRodelo, F. (2008). Ejercicio de la libertad de prensa y sus limitaciones en entornos violentos. El caso de los periodistas de Culiacán, Sinaloa, México. Tesis para obtener el grado de Maestra en Ciencias Sociales. Universidad de Guadalajara, CUCSH.

Sánchez, V. (2011). La actual lucha del gobierno mexicano contra la delincuencia en la frontera con Estados Unidos. Frontera Norte, vol. 23, Núm. 45, enero-junio. 97-130. 
Sanmartín, J. (2010). “Concepto y tipos de violencia”. En J. Sanmartín, R. Gutiérrez, J. Martínez y J. L. Vera (Eds.), Reflexiones sobre la violencia (pp. 11-33). México: Siglo XXI.

Sierra, A. (2010a). Peligros y paradojas de la cobertura del narcotráfico. En Periodismo en tiempos de amenazas (pp. 9-14). Center for Journalism in the Americas, University for Texas at Austin.

Sierra, A. (2010b). ¿Hay una narrativa periodística independiente sobre las drogas? Las curiosas paradojas de la cobertura del narcotráfico. En Cobertura del narcotráfico y el crimen organizado en Latinoamérica y el Caribe. 8th Austin Forum on Journalism in the Americas. Knight Center for Journalism in the Americas, University for Texas at Austin (17-18 de septiembre de 2010). Pp. 33-56.

Stratfor (2012). Polarization and Sustained Violence in Mexico's Cartel War, reporte consultado online. Recuperado de http://www.stratfor.com/sample/analysis/polarization-and-sustainedviolence-mexicos-cartel-war (14/09/2102).

Turati, M. (2010). Reportear la sangre a la luz de los derechos humanos. En Derecho a la libertad de expresióny el ejercicio periodístico (pp. 57-72). México: OACNUDH-Oficina en México del Alto Comisionado de las Naciones Unidas para los Derechos Humanos.

Trujillo, G. (2000). La canción del progreso. Vida y milagros del periodismo bajacaliforniano. Tijuana, B. C.: Larva/Instituto Municipal de Arte y Cultura.

UnEs CO (1983). Código Internacional de Ética Periodística. Recuperado de http://www.docencia. unt.edu.ar/eticaylegislacion/content/cod_etica_unesco.doc.

Waisbord, S. (2000). Repensar la prensa en las democracias latinoamericanas, en Sala de Prensa, número 22, agosto, año III, vol. 2. Recuperado de www.saladeprensa.org.

Weber, M. (1979). El político y el científico. Madrid: Alianza Editorial.

Zizek, S. (2009). Sobre la violencia. Seis reflexiones marginales. Barcelona: Paidós.

\section{Entrevista personal}

Enrique Sánchez Díaz, periódico El Mexicano de Tijuana entrevistado para esta investigación en octubre de 2011. Tijuana, Baja California. 